Ribeiro D.M., Salama A.A.K., Vitor A.C.M., Argüello A., Moncau C.T., Santos E.M., Caja G., Oliveira J.S., Balieiro J.C.C., Hernández-Castellano L.E., Zachut M., Poleti M.D., Castro N., Alves S.P., Almeida A.M. 2020. The application of omics in ruminant production: a review in the tropical and sub-tropical animal production context. Journal of Proteomics 227: 103905. https://doi.org/10.1016/j.jprot.2020.103905

\title{
The application of omics in ruminant production: a review in the tropical and sub- tropical animal production context
}

Author links open overlay panelDavid M.RibeiroaAhmed A.K.Salama ${ }^{\mathrm{b} A n a}$

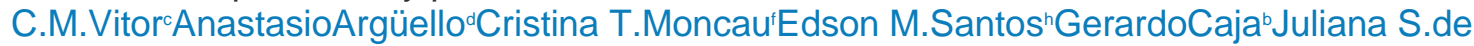

Oliveiranúlio C.C.Balieiro̊Lorenzo E.Hernández-Castellano®MayaZachutiMirele

D.PoletiłNoemiCastro`Susana P.Alves'André M.Almeidaa

Show more

Add to Mendeley

Share

Cite

https://doi.org/10.1016/i.jprot.2020.103905Get rights and content

\section{Highlights}

Tropical animal production systems are subjected to harsh conditions that limit production sustainability

Omics technologies provide insight to resilience mechanisms and product quality at the molecular level

Application of omics in the tropical animal production context could help improve the productivity of low-resource areas

\section{Abstract}


The demand for animal products (e.g. dairy and beef) in tropical regions is expected to increase in parallel with the public demand for sustainable practices, due to factors such as population growth and climate change. The necessity to increase animal production output must be achieved with better management and production technologies. For this to happen, novel research methodologies, animal selection and postgenomic tools play a pivotal role. Indeed, improving breeder selection programs, the quality of meat and dairy products as well as animal health will contribute to higher sustainability and productivity. This would surely benefit regions where resource quality and quantity are increasingly unstable, and research is still very incipient, which is the case of many regions in the tropics. The purpose of this review is to demonstrate how omics-based approaches play a major role in animal science, particularly concerning ruminant production systems and research associated to the tropics and developing countries.

\section{Significance}

Environmental conditions in the tropics make livestock production harder, compared to temperate regions. Due to global warming, the sustainability of livestock production will become increasingly problematic. The use of novel omics technologies could generate useful information to understand adaptation mechanisms of resilient breeds and/or species. The application of omics to tropical animal production is still residual in the currently available literature. With this review, we aim to summarize the most notable results in the field whilst encouraging further research to deal with the future challenges that animal production in the tropics will need to face.

\section{Graphical abstract}




\section{Heat stress and chans ng climate}

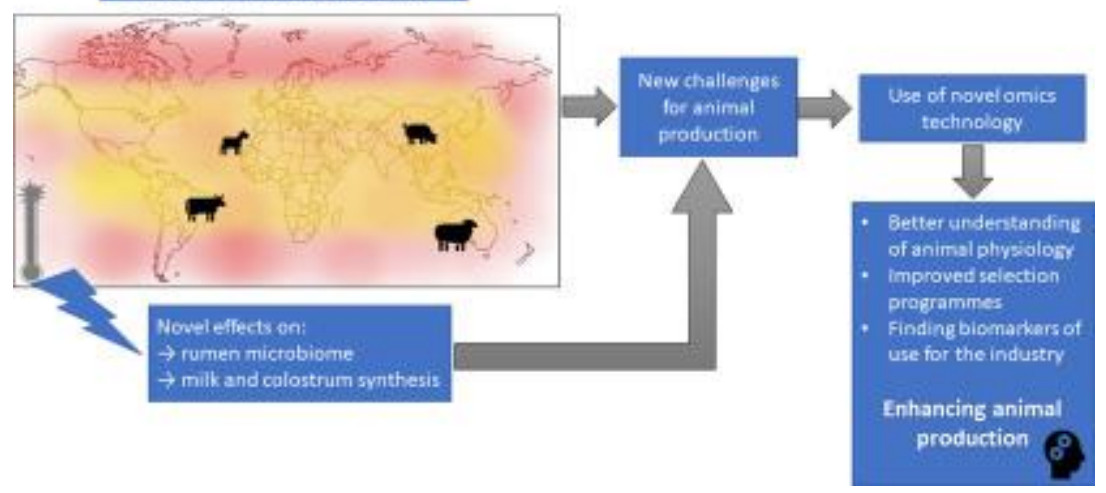

1. Download : Download high-res image (145KB)

2. Download : Download full-size image

- Previous article in issue

- Next article in issue

\section{Keywords}

Tropics

Ruminants

Genomics

Transcriptomics

Proteomics

Metabolomics

\section{Introduction}

Animal production in tropical countries plays a pivotal role in providing valuable protein for local populations. In the coming years, animal production will face two major challenges: a rising human population and an increasing need to reduce greenhouse gas emissions [1]. Thus, the demand for animal products will increase along with the need to reduce emissions, such as methane, that ruminant production is responsible for, particularly beef and dairy intensive production. Simultaneously, problems such as heat stress (HS) will become more frequent, providing additional challenges that must be dealt with. Animal production in the tropics is already difficult compared to temperate regions due conditions such as higher HS and water scarcity. When combined with the predicted environmental changes, these conditions 
make research and technical based approaches in different fields essential to improve productivity and sustainability. The physiological adaptation to external factors and the description of suitable biomarkers to predict meat quality traits and animal welfare are good examples of such subjects that need further investigation in this context. These issues have caught the attention of the scientific community [1, 2$]$.

The use of novel omics technologies is becoming increasingly common in the context of animal production. Genomics, transcriptomics, proteomics and metabolomics, in addition to other omics subjects such as phosphoproteomics, peptidomics or lipidomics, have all been used in the field of animal production. The use of these omics technologies allows the study of animal metabolism when subjected to a certain factor. This allows the study of the impact of environmental conditions (e.g. temperature, humidity), nutrition, gender and welfare, on the physiology of farm animals at the molecular level. For example, genomics allows the identification of candidate genes related to a desirable trait in reproduction programmes, such as fertility. The postgenomic tools then allow the identification of differentially expressed genes and differentially abundant proteins and metabolites between two conditions of a certain factor. Furthermore, the integration of these technologies provides a full screening of the animal, tissue or cell metabolism, from genotype to phenotype. Omics-derived biomarkers, for example, allow traceability and quality monitoring throughout the pork production chain [3] . Moreover, using proteomics, the quality of dairy and meat products can be analysed by identifying the proteins behind desirable traits such as milk protein composition and meat tenderness [4]. Several omics applications in animal science have been extensively reviewed in recent years [[4], [5], [6], [7], [8], [9], [10]]. However, animal production integrated with omics approaches have been given less focus in a tropical and sub-tropical animal science context. Such focus is very specific and considerably different from the ones found in temperate regions in developed countries. Literature is plentiful of examples (Table 1). They include for instance heat stress in large and small ruminants, seasonal weight loss in small ruminants under extensive systems or the disadvantages of harsh environments on product quality. These are some of the subjects that are yet to be reviewed and studied to a similar extent to other subjects of temperate climates. Analysing these subjects from a molecular biology-driven perspective, allows the generation of information that would greatly benefit regions where productivity is 
generally low. For example, the study of breeds more resistant to HS or weight loss and their physiology, could help improve the productivity of a region that largely uses susceptible breeds. Other closely related areas such as epigenetics/epigenomics will not be considered in this study. The use of epigenomics, or the study of the epigenome, allows the identification of gene expression modifications that do not result from DNA mutation, which modify a phenotype. The epigenome is the set of modifications such as DNA methylation that might transmit epigenetic information such as non-coding RNA. DNA methylation for example is a reaction catalysed by DNA methyltransferases. Methylation of promotor regions inhibits gene expression, whereas hypomethylation increases gene expression [11], which could be a causative factor for different gene expression of the same gene in different tissues. Liu et al. [12] found that DNA methylation regulated EEF1D gene expression, who is positively related to milk production traits such as milk yield, in dairy cows. Extensive reviews on the subject are well documented $[\underline{11}, \underline{13}, \underline{14}]$ and readers are directed to them for further references.

Table 1. Studies in currently available literature that study topics of relevance for animal science in the tropics and sub-tropics, using omics technology.

\section{Area of animal science}

\section{Omics field}

Transcriptomics

Proteomics

Metabolomics

Meat quality in Bos

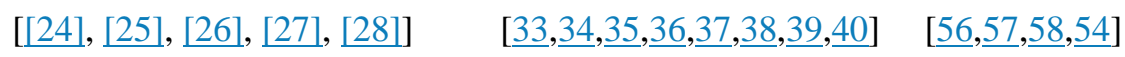

$[\underline{60}, \underline{61}, \underline{62}, \underline{63}]$ indicus

Heat stress in dairy cows

Heat stress in dairy goats Seasonal weight loss in small ruminants

Colostrum nutrition

Genomics ,$\underline{58,54]}$

$[\underline{70}, \underline{67}, \underline{75}, \underline{76}, \underline{77}, \underline{78]}$ $[69,74]$

$[\underline{84}, \underline{86}, \underline{87}]$

$[\underline{89}, \underline{11}]$

$[\underline{101}, \underline{102}, \underline{103}, \underline{104}, \underline{109}, \underline{110]}[\underline{105}, \underline{108}]$

[127]

$[117,118,119, \underline{121}, \underline{122}, 123][124,125,126]$ 
Area of animal science
Genomics
Omics field

Transcriptomics

Proteomics

Metabolomics

Rumen

microbiota

[160]

$[\underline{166}, \underline{167,168,169]}$

$[\underline{161}, \underline{170}, \underline{171}, \underline{172}, \underline{173}]$

Tick

Borne

diseases $[\underline{185}, \underline{186}, \underline{187}, \underline{188}, \underline{191}, \underline{198}, \underline{199}] \quad[178, \underline{180}, \underline{184}, \underline{197}, \underline{202}, \underline{203}][1 \underline{176}, \underline{177}, \underline{182}, \underline{183}, \underline{195}, \underline{201]}$ [200]

and

helminths

This review aims to describe subjects of importance for animal production in the tropics and sub-tropics, studied using omics technologies (Fig. 1). Overall, we aim to demonstrate its relevance in answering complex questions on how animal production in the tropics and sub-tropics could benefit from these endeavours. We also reviewed two case studies of tick-borne diseases and gastrointestinal parasites. Albeit not strictly being within the scope of this review. However, because animal health significantly influences animal productions, they were also included.

ANIMAL EXPERIMENTS

-Nutrition

-Genetics

-Health \& Welfare

\section{GENOMICS}

Genome wide association studies (GWAS)

> Association between SNP's and a phenotype. Metagenomics

- Allows the phylogenetic characterization of complex microflora (e.g. rumen, caecum).

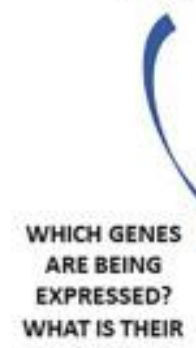
FUNCTION?

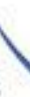

D? N?

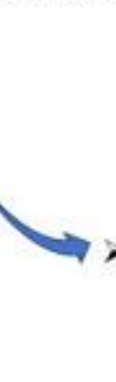

Screening of differentially expressed or coexpressed genes in response to a certain condition or in relation to a phenotype.
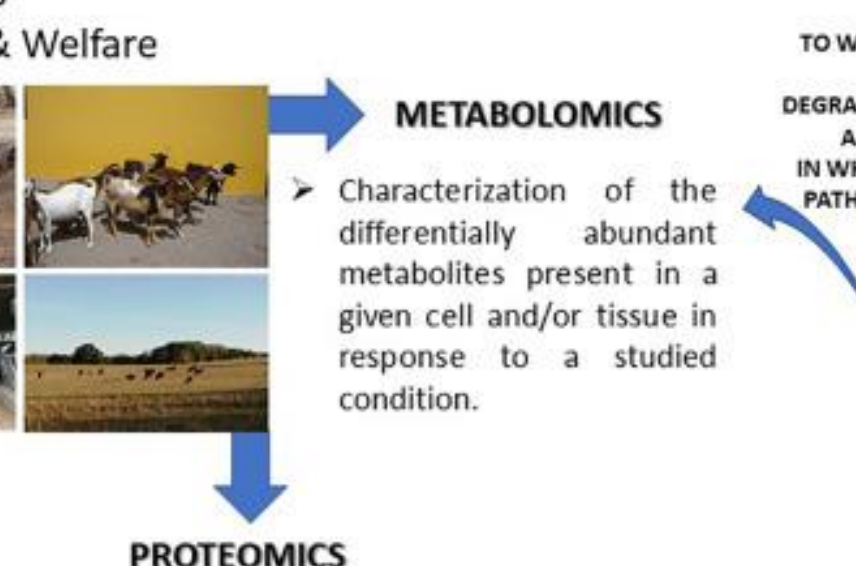

DEGRA

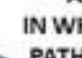

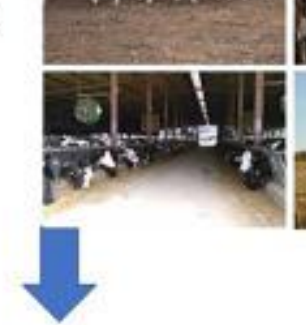

TRANSCRIPTOMICS

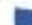

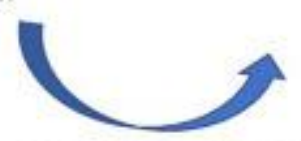

WHICH GENES ARE BEING TRANSLATED INTO PROTEINS?
ARE THERE POST-TRANSLATION MODIFICATIONS?
WHAT ARE THE FUNCTIONS OF THE EXPRESSED PROTEINS?

1. Download: Download high-res image (351KB)

2. Download : Download full-size image 
Fig. 1. Systems biology network applied to animal science experiments.

\section{Omics and meat quality traits in Bos indicus}

Bos indicus breeds (Zebu cattle) are extensively used for beef production in tropical and sub-tropical environments, due to their thermotolerance and resistance to parasites [15]. Zebu breeds descend from South Asian ancestors and are characterized by a cervo-thoraxic hump and long wide ears [16]. They are the predominant breed type in countries with important beef cattle populations such as Australia or Brazil, where the dominant breed is the Nellore cattle. Although breed differences in meat quality traits have been well documented [[17], [18], [19], [20]], Zebu cattle have a particular reputation for producing carcass and meat of low-quality grades when compared to Bos taurus [[21], [22], [23]]. For this reason, animal geneticists are being led to conduct considerable efforts to increase the knowledge of the genetic architecture and biological pathways that control the variation of these production traits. However, the application of traditional selection methods to these traits is expensive and requires animal slaughtering. Fig. 2 shows some of the most relevant results obtained using omics to study meat quality.

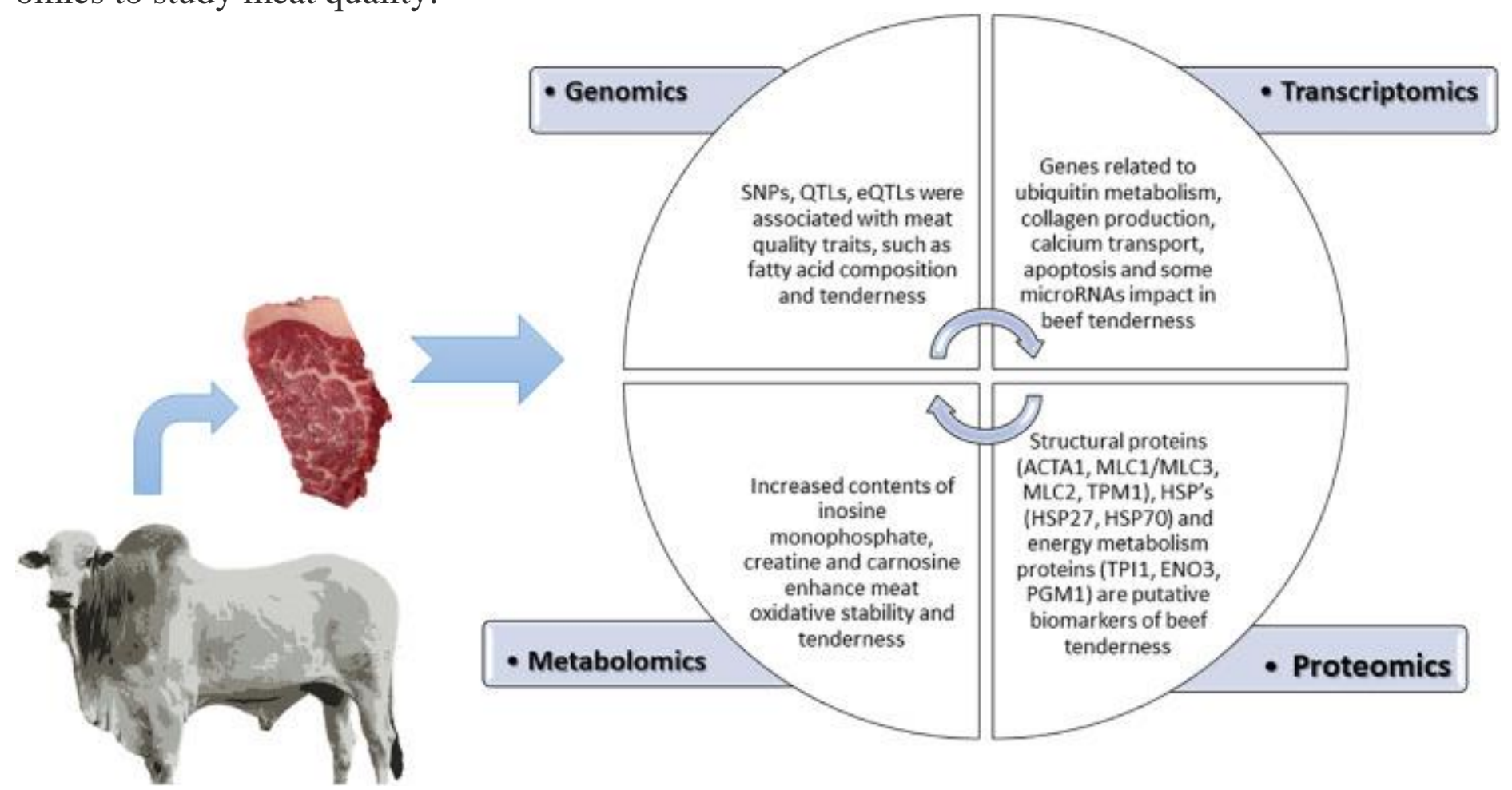

1. Download : Download high-res image (225KB) 


\section{Download : Download full-size image}

Fig. 2. Overview of omics results found for meat quality of Zebu cattle. The development of high-density bovine genotyping arrays [24] and the use of genome-wide association studies (GWAS), have allowed the identification of genomic regions associated with meat quality phenotypes for Bos indicus animals, suggesting candidate genes for fine mapping. Cesar et al. [25] reported 23 genomic regions (1$\mathrm{Mb}$ windows $)$ in Nellore steers $(\mathrm{n}=386)$ that explained $\geq 1 \%$ of the genetic variance for intramuscular fat (IMF) deposition and fatty acids (FAs) composition using 449,363 single nucleotide polymorphisms (SNPs). Ten genomic regions were furthermore reported for monounsaturated fatty acids (MUFA) and nine genomic regions were described for a group of polyunsaturated fatty acids (PUFA). This information benefits selection programs to which meat fatty acid composition is a factor to take into consideration in breeding cattle. These authors commented that many of these regions were not previously detected in other cattle breeds. Another study with FAs composition using 470,007 SNPs in Nellore bulls $(\mathrm{n}=1,556)$ found 115 windows that explained more than $1 \%$ of the additive genetic variance for the 22 studied FAs [26]. Nineteen genomic regions distributed in 16 different chromosomes were associated with MUFAs, 40 genomic regions with PUFAs, and 21 genomic regions accounted for the group of omega-3, omega- 6 , and the n-6:n-3 ratio. Both authors $[25,26]$ concluded that the identification of the genomic regions and their respective candidate genes improved the genetic basis of the FAs profile of the Nellore cattle, contributing to increase meat quality and human health. Other studies were also conducted to relate gene expression with meat tenderness. Tizioto et al. [27], studying the association among 651,259 SNPs and meat quality traits in Nellore steers $(\mathrm{n}=425)$, found that the shear force measured at $24 \mathrm{~h}, 7$ and 14 days postmortem was primarily influenced by quantitative trait loci (QTL) of small effect. The largest effects explained were from $0.10 \%$ (shear force at 7 days postmortem) to $0.19 \%$ (shear force at 14 days postmortem) of the additive genetic variance. A total of 56 genes were detected as candidates for meat tenderness, which were related to the regulation of transcription, membrane region and metal-binding. Meanwhile, Magalhães et al. [28] identified genomic regions that explained 3.89\% and $3.80 \%$ of the additive genetic variance for marbling $(n=1,633)$ and meat tenderness $(\mathrm{n}=1,630)$ in Nellore cattle. One window that explained $1.12 \%$ of the 
additive genetic variance for marbling was the third largest effect window (0.67\%) for meat tenderness, suggesting that the SNPs associated to the candidate genes exert a pleiotropic effect on both traits. The authors reported that the genes that were found associated with marbling do not correspond to those described in others GWAS in Bos taurus. Regarding meat tenderness, only the solute carrier family 27 -member 2 (SLC27A2) gene had already been associated with meat tenderness in cattle. These articles summarized that two variations have occurred when we evaluate the effects of SNP markers for the same meat quality trait. First, there is a variation in effects within the same breed of Bos indicus cattle, which can be attributed to the differences in SNP allele frequencies, linkage disequilibrium between SNPs and causal variants, coverage of the SNP chip for the breed, analysis method, and population size. Second, and probably the most important, distinct genomic regions are segregating between Bos taurus and Bos indicus cattle [29]. In this sense, and by reducing the cost of genome sequencing, fine mapping of specific regions [30] or whole-genome sequencing [31], new causal mutations could be included in customized low-density chips to enable large-scale use for genetic evaluation for meat quality.

High throughput sequencing technologies have been widely used to study gene expression of the genome and characterize the development of phenotypes [32]. Transcriptome studies in the Bos indicus breeds have focused on reproductive traits $[\underline{33}, \underline{34}]$, feed efficiency $[\underline{35}, \underline{36}]$, mineral concentration $[\underline{37}, \underline{38}]$, and meat quality [39,40]. Accordingly, Cesar et al. [41] studied the gene expression of the skeletal muscle in Nellore cattle with divergent IMF deposition. The authors identified retinoic acid and inflammatory cytokine pathways, as well as insulin-like growth factor 2 (IGF2) and ankyrin repeat domain 26 (ANKRD26) genes as important regulators of the IMF content variation. A similar study was conducted to identify hub genes based on the gene co-expression network analysis obtained from differentially expressed genes associated with IMF content in Nellore cattle [42]. According to the authors, phosphodiesterase 4D (PDE4D), kelch-like family member 30 (KLHL30), and interleukin 1 receptor accessory protein $(I L 1 R A P)$ were highly interconnected with nodes in a network, demonstrating to be functionally significant on the lipid metabolism in the Nellore cattle. The identification of these genes and their functions provides information that not only serves to complement other findings that confirm 
gene expression (e.g. proteomics) but complement useful information towards the identification of desirable genes to produce meat with high IMF content.

Recently, the FAs profile in beef has received considerable attention because of its implication in human health, besides its role in the tenderness and juiciness of cooked meat [43]. Among the studied FAs, a larger number of differentially expressed genes in skeletal muscle was observed for the oleic acid content variation in zebu cattle [44,45], and most of these genes were related to oxidative phosphorylation, ribosome, and proteasome biological processes [23]. Moreover, Cesar et al. [46] promoted the integration of high throughput DNA genotyping and RNA-sequencing data. The authors identified three transcription factors (EGR4, USF1, and RUNX1T1) within the eQTLs (expression quantitative trait loci) hotspots regions with known functions in lipid metabolism. The identification of these genes and their relation with healthier fatty acids ultimately contributes to improve meat quality through the selection of breeds that have increased expression of genes that contribute towards increased concentration of bennecial fatty acids, mainly PUFA.

Transcriptomics has been used to characterize gene expression changes related to meat tenderness. Genes related to ubiquitin metabolism, transport of molecules, and collagen production were identified as involved in meat tenderness in Nellore bulls [39]. In a recent study using Nellore steers, Gonçalves et al. [40] found apoptosis, calcium transport, and proteolysis pathways associated with shear force measured at 14 days of aging. These authors identified two microRNAs (bta-mir-133a-2 and bta$m i-22$ ) and three genes (myoglobin, enolase 3, and carbonic anhydrase 3) as potential regulator transcripts of pathways impacting tenderness by the gene co-expression network analysis. A similar study was conducted to analyze the relationship among genes expressed in skeletal muscle of Nellore steers with meat quality traits and mineral concentration, but using weighted correlation network analysis [47]. The modules containing co-expressed genes associated with two or more minerals, meat tenderness, and IMF were enriched to AMPK (AMP-activated protein kinase) and mTOR (mammalian Target of Rapamycin) signaling pathways, and ubiquitinmediated proteolysis.

The role of microRNAs (miRNAs), small noncoding RNAs, in meat tenderness was also investigated in zebu cattle by Kappeler et al. [48]. In this study, two miRNAs (bta-mir-182 and bta-mir-183) were upregulated in animals with higher tenderness at 
14 days of aging. In contrast, one miRNA (bta-mir-338) was downregulated in the same group. Calpain (CAPN5), calpastatin (CAST), and caspases (CASP2 and CASP9) were identified as target genes of these miRNAs, suggesting their involvement in the regulation of the apoptosis processes and meat tenderization. Since these enzymes contribute for a significant role in muscle to meat proteolysis and its transformation into meat, knowing their regulation mechanisms is critical to maximize the output of high quality products, which greatly impacts profitability throughout the production chain.

In addition, transcriptome differences have also been achieved for carcass traits. For instance, Silva-Vignato et al. [49] conducted a study of the skeletal muscle transcriptome of Nellore cattle using RNA-sequencing. The authors found 101 differentially expressed genes for the ribeye area (REA) and 18 for backfat thickness (BFT). The results included genes involved in MAPK (mitogen-activated protein kinase) signaling and endocytosis pathways regulating the REA trait; and the biological processes related to adipogenesis and muscle growth controlling the BFT trait. Indeed, energy and lipid metabolism pathways, as well as inflammation and immune response pathways in skeletal muscle were found to modulate the BFT trait in Nellore cattle [ $\underline{50}, \underline{51}]$.

Among the omics tools, proteomics has been extensively used in meat science in the last two decades because proteins and enzymes have essential roles in muscle to meat transformation [[52], [53], [541]. Changes in Longissimus thoracis muscle protein profile related to ultimate $\mathrm{pH}$, and consequently, to meat quality traits were observed in a study with Nellore cattle [55]. In this context, the alpha-actinin-2 (ACTN2), histone $\mathrm{H} 2 \mathrm{AJ}$ (H2AFJ), UTP-glucose-1-phosphate uridylyltransferase (UGP2) and voltage-dependent anion-selective channel protein 3 (VDAC3) proteins that presented differential abundance between the ultimate $\mathrm{pH}$ groups were also correlated with some meat quality attributes, such as colour and tenderness. These proteins could be interesting candidates for validation of biomarkers that indicate the desirable traits mentioned.

Carvalho et al. [56], comparing extreme groups for meat tenderness (shear force measured at 7 days of aging), identified heat shock protein beta 1 (HSP27), and heat shock 70 Da protein 1A (HSP70-1), as well as structural proteins (ACTA1, MLC1/MLC3, MLC2, TPM1) as potential biomarkers for meat tenderness in 
Nellore bulls. Comparative analysis between Bos taurus (Angus) and Bos indicus (Nellore) cattle using a phosphoproteomic approach showed that differences in meat quality between the two breeds could be attributed to proteins involved in contraction and muscle organization, cell flux of calcium and apoptosis. Authors highlighted proteins phosphoglucomutase-1 (PGM1), triosephosphate isomerase (TPI1), and 4-3-3 \& protein (YWHAE) that showed differences in phosphorylation [18]. In addition, a metalloproteins study of the Nellore cattle muscle, identified piruvate kinase $(P K M)$ and albumin $(A L B)$ as calcium-dependent proteins related to differences in meat tenderness [57].

In an in-depth study, proteomics was used as a tool to understand changes in the Longissimus thoracis muscle protein profile of the Nellore bovine with contrasting genotypes for calpain-1 (CAPN4751) and calpastatin (UOGCAST) molecular markers [58]. The results indicated differentially abundant proteins for the effect of interaction among molecular markers, including myosin (MYL2, MYLPF, and MYH6) isoforms, actin (ACTA1), troponin-T (TNNT3), heat shock proteins (HSP27), and energy metabolism proteins (TPI1, CKM, ENO3, UQCRC1, TRIM72) [54].

Differences in IMF deposition in zebu cattle have been evaluated by an innovative proteomic approach. The authors that performed this study used a Nellore cattle Longissimus dorsi muscle transcriptome database to identify the proteins dataset [59]. Furthermore, the integration of protein, mRNA, and miRNAs data was performed to explain intramuscular fat deposition. The results revealed 164 differentially abundant proteins between the divergent groups for IMF deposition, 17 genes differentially expressed at the mRNA and protein levels, and two genes whose miRNAs could explain the inconsistent expression of mRNA and protein levels. Proteins involved in glycolysis metabolism, actin cytoskeleton signaling, cell-cell adherent junctions and pathways for MAPK and insulin were associated with IMF content variation.

Metabolomics is being increasingly used in livestock research [9]. However, there is a surprising gap in studies evaluating meat quality traits in cattle. Connolly et al. [60], using proton nuclear magnetic resonance ( ${ }^{\mathrm{H}} \mathrm{NMR}$ ) spectroscopy, tested the relationship among blood metabolites and carcass and production traits at different feeding days in Wagyu crossed with other breeds, including Brahman cattle (Bos indicus). The analyses revealed that genotypes have a significant influence at the 
concentration of sixteen from the 35 metabolites identified. The metabolites 3hydroxybutyrate, acetate, and propionate were the most promising metabolites to predict marbling.

In Nellore cattle, the supplementation of the animal diet with yerba mate grass (Ilex paraguariensis) extract improved meat tenderness and oxidative stability due to the increased levels of inosine monophosphate, creatine, and carnosine in fresh meat [61]. Meat metabolite profiles were compared between Nellore and crossbred Angus $x$ Nellore cattle [62]. A set of 15 metabolites differed between the studied breeds. These included acetate, carnosine, glutamate, carnitine, creatinine, and isoleucine, which were correlated with beef sensory properties (overall liking, juiciness, tenderness, and flavor) in the other study conducted using the same animals by the same research group [63].

Despite the technological innovations and significant advances in omics sciences for meat quality in Bos indicus cattle, one of the limiting factors is that all the predicted genetic polymorphisms, genes, transcripts, proteins, and metabolic pathways have been identified in Bos taurus database. It should be of utmost priority to establish a dedicated Bos indicus database in order to obtain accurate gene/protein identifications. This would provide higher confidence in the results obtained. Moreover, it would validate these results to design practical applications in the improvement of breeder selection programmes, meat quality assessment, among others.

\section{Heat stress in dairy cows: an omics approach}

Heat stress is the main abiotic stressor for high-yield dairy cows (e.g. HolsteinFriesian), as they are extremely sensitive to hot environments due to their increased metabolic rate [64]. In the near future, climate change is predicted to increase the prevalence and intensity of HS periods [65]. Therefore, dairy cattle will become more susceptible to suffer from HS. Despite advances in cooling systems during summer, HS continues to be an important confounder of performance in dairy cows, with significant cost consequences for the dairy industry [66] in both tropical and temperate regions. Dairy cattle experience HS when they are exposed to environmental conditions above their thermo-neutral zone. Generally, a thermal heat index (THI), a measure that includes temperature and humidity, above 72 is 
considered as a HS condition for dairy cows [67]. In addition to THI, thermal radiation is a main HS factor in warm environments [68]. In many countries worldwide, a high THI coupled with elevated thermal radiation are maintained for weeks during the summer season causing a chronic HS on cows. It is extremely important to distinguish between the effects of an acute HS (hours to days) and chronic HS (weeks to months, as in the summer season), since the physiological responses to chronic stress are adaptive and related to a prolonged exposition to the stressor. Therefore, we will clearly state the experimental condition of each referred study. This section will focus on studies that assessed the effects of HS on dairy cows as reflected by omics techniques (metabolomics and proteomics) of biological fluids and tissues of dairy cows under HS (Fig. 3).

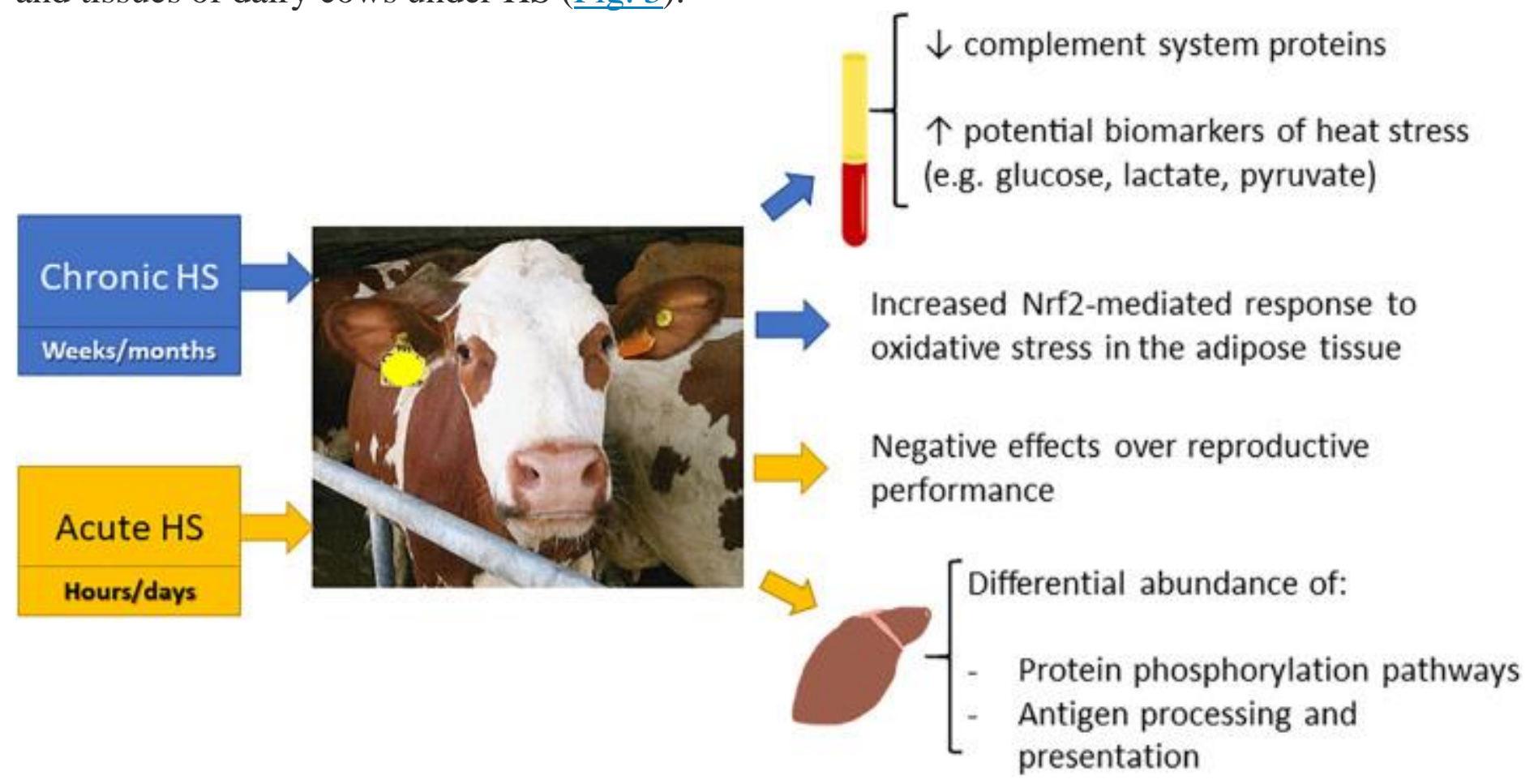

1. Download : Download high-res image (253KB)

2. Download : Download full-size image

Fig. 3. Effect of different types of heat stress (HS): chronic (blue) of acute (yellow), over dairy cows' metabolism.

3.1. Metabolomics and proteomics of plasma, milk and follicular fluids in heatstressed dairy cows 
The effects of chronic HS on the metabolomics of plasma in dairy cows was examined by Tian et al. [69], that used integrated 'H NMR and liquid chromatography-mass spectrometry techniques. In their study, the non-HS group were mid lactation Holstein cows during the spring season and the HS cows were sampled during the summer season (THI 68 to 80). The authors reported 41 metabolites that had differential abundance between plasma of HS and non-HS cows, from them 13 metabolites, including trimethylamine, glucose, lactate, betaine, creatine, pyruvate, acetoacetate, acetone, $\beta$-hydroxybutyrate, C16 sphinganine, lysophosphatidylcholine (18:0), phosphatidylcholine (16:0/14:0), and arachidonic acid, had high sensitivity and specificity in HS cows. These metabolites are involved either in carbohydrate, amino acid, lipid, or gut microbiome-derived metabolism and they are likely to be considered as potential biomarkers of HS dairy cows, indicating that HS affects different metabolic pathways in lactating dairy cows. However, these results would benefit from studies seeking the validation of the previously mentioned metabolites as HSindicating biomarkers. A good way to complement these results and take sturdier conclusions is studying this issue using proteomics.

Proteomic analysis of plasma was also used to assess the effects of chronic HS on dairy cows, using isobaric tags for relative and absolute quantification (iTRAQ). In this work, plasma was sampled from mid lactation Holstein cows that were either HS during summer (THI 80-88) or non-HS during spring (THI 50). Overall, 1472 plasma proteins were identified, from which 85 were differentially abundant in HS cows [70]. Several factors in the complement system (including C1, C3, C5, C6, C7, C8, and C9, and complement factor $\mathrm{B}$ and factor $\mathrm{H}$ ) were found to be downregulated in plasma of HS cows compared to those from non-HS cows [70]. In another study that used twodimensional electrophoresis (2-DE) combined with mass spectrometry (MS), the effects of chronic HS on plasma proteomics were also examined in mid lactation Holstein cows. The sampling of plasma was defined at two time points: at the beginning of a moderate HS in summer (average THI $=80$ ); and after 23 days of HS, compared to plasma that was collected during spring (THI 50-60) [67]. It was found that seven proteins were differentially abundant at the beginning of HS compared to spring, and three proteins were less abundant after 23 days of HS compared to the beginning of HS [71]. Among them, a decrease in the abundance of transthyretin, which is known to be reduced by inflammation [72], was found in HS cows [71]. In 
addition, increased levels of the pro-inflammatory cytokines tumour necrosis factor (TNF- $\alpha$ ) and interleukin-6 (IL-6) were found in plasma of the heat stressed cows [71]. Taken together with the previous findings, proteomic analyses of plasma demonstrate that chronic HS in summer may increase subacute inflammation and may also impair immune function in lactating dairy cows [73].

To examine the effects of chronic heat stress on milk metabolomics in mid lactation dairy cows, milk was sampled in summer (HS; THI 68-80) or spring (THI 50-55) [74]. A total of 53 metabolites were different in milk of HS cows, involved in carbohydrate, amino acid, lipid, and gut microbiome-derived metabolism. These altered pathways were similar to those found by metabolomics analysis of plasma in HS cows [69]. Indeed, significant correlations between the levels of lactate, pyruvate, creatine, acetone, $\beta$-hydroxybutyrate, trimethylamine, oleic acid, linoleic acid, lysophosphatidylcholine 16:0, and phosphatidylcholine 42:2 were found between plasma and milk of HS cows. This may indicate that these metabolites in milk represent the metabolomics alterations in blood during HS. More studies investigating the effects of HS on milk metabolomics are needed in order to fully describe and validate biomarkers of HS in milk. The use of these biomarkers could be useful in assessing management strategies for mitigation of HS on dairy farms.

Effects of acute HS on the proteome of ovarian follicular fluids was examined recently by Rispoli et al. [75]. In that study, Holstein cows were either maintained at thermo-neutral conditions $(\mathrm{THI}=\sim 67$ ) or exposed to acute HS for $\sim 12$ hours $(\mathrm{THI}=$ 71 to 86). Dominant follicle collection was conducted, and the follicular fluid proteome was evaluated by quantitative tandem mass spectrometry (nano LCMS/MS) [75]. Four proteins were found to be upregulated in the follicular fluids of acute-HS cows (kininogen-2, serotransferrin, serglycin and syndecan), whereas numerous cytokeratins, myosin 18B, histidine-rich glycoprotein, alpha-2macroglobulin, cathespin B and pleiotrophin were downregulated in acute-HS cows [75]. These changes in the proteome of follicular fluids under acute heat stress may have an impact on the competence of the periovulatory follicle, supporting the well described detrimental effects of acute HS on the reproductive system in dairy cows.

\subsection{Proteomics of liver and adipose tissues in heat-stressed cows}


The effects of chronic HS during the dry period on the liver proteome in Holstein dairy cows was examined by Skibiel et al. [76]. These authors found differential abundance of 75 out of 3,270 proteins in liver samples collected in postpartum cows that were either housed with cooling devices or not (HS cows) during the dry period. Some of the most affected pathways were related to oxidative phosphorylation, mitochondrial dysfunction, farnesoid $\mathrm{X}$ receptor/retinoid $\mathrm{X}$ receptor (FXR/RXR) activation, and the methylmalonyl pathway [76]. This indicates that alleviating HS by cooling cows during the dry period likely improved ATP production, reduced oxidative stress, and prevented excessive accumulation of hepatic triglycerides and cholesterol. In another study, Ma et al [77] examined the effects of short-term acute HS using iTRAQ proteomics. The study comprised two experimental periods ( 9 days in climatic chamber and 30 days on thermoneutrality) with two groups of multiparous Holstein cows: acute-HS $\left(32-36^{\circ} \mathrm{C}\right)$ and thermal-neutral $\left(20^{\circ} \mathrm{C}\right)$ cows. This study showed changes in the liver protein abundance. Main regulated pathways were involved in oxidative phosphorylation and antigen processing and presentation pathways [77]. These studies indicate that HS affects the liver proteome by altering oxidative phosphorylation. However, the differences between experiments regarding the duration of the HS (acute vs. chronic) and in the lactation stage of the cows (transition vs. mid lactation) difficult further interpretation.

The effects of chronic HS during summer on the proteome of adipose tissues in late gestation Holstein cows was investigated by using intensity based, label-free, quantitative shotgun proteomics (nano-LC-MS/MS) of subcutaneous adipose tissues of prepartum cows [78]. In that study, 107 out of 1495 proteins were differentially abundant in the adipose tissues of HS late gestation cows compared to late pregnant cows in winter, and the top canonical pathways enriched were Nrf2-mediated oxidative stress response, acute-phase response, and FXR/RXR and LXR/RXR activation [78]. Concerning the enrichment of the Nrf2-mediated oxidative stress response in adipose tissue from HS cows, the transcription factor Nrf2 is one of the key antioxidant regulators in the body, responding to oxidative stress by activating antioxidant genes [79]. These findings suggest that the regulatory adaptation to chronic HS and increased oxidative stress during summer is done in parallel with changes in the adipose tissue proteome in late pregnant cows. After validation, these proteins may serve as biomarkers of HS in adipose tissues. 
In conclusion, several studies in recent years have evaluated the effects of acute and chronic HS on the metabolome and the proteome of different biological fluids (i.e. plasma, milk and follicular fluids) and tissues (i.e. liver and adipose tissues) of dairy cows. These studies highlight the ability of omics techniques to add valuable information on metabolites and proteins that are affected in dairy cattle during HS. Additional studies utilizing these high throughput methods are needed to have a broad omics database that may be used to develop new approaches to alleviate the effects of HS on dairy cows.

\section{Omics in the context of heat stress: dairy goats as a model}

As mentioned before, HS negatively affects the productivity, health, and welfare of dairy animals $[\underline{80}, \underline{81]}$. Despite advances in cooling systems and the implementation of several strategies, HS constitutes a significant cost for the dairy industry [66].

Compared to cows, dairy sheep and goats are less sensitive to HS. Furthermore, goats are considered more tolerant to high ambient temperature than sheep due to the fact that goats have lower metabolic rate and higher water-conservation capacity [82]. Nevertheless, significant milk yield losses and milk quality impairment have been reported in HS dairy goats $[\underline{83}, \underline{84}]$ and sheep [ $\underline{85}]$.

With regard to the application of omics in HS small dairy ruminants, only a few studies have been carried out. Herein we will present results on the omics of blood, milk, and urine of dairy goats. Omics can shed more light on the physiological mechanisms that occur in animals when exposed to HS, which helps in the establishment of effective strategies to alleviate its negative effects.

\subsection{Heat stress and milk synthesis}

Dairy animals produce less milk with lower contents of fat and protein under HS conditions $[\underline{83}, \underline{86}]$. By means of omics we were able to demonstrate that HS impairs cellular and molecular processes in mammary cells. Salama et al. [6] tested RNA-seq of milk cells collected from goats under HS $\left(30\right.$ to $\left.37^{\circ} \mathrm{C}\right)$ and thermal-neutral (TN; 15 to $20^{\circ} \mathrm{C}$ ) conditions. Heat stress changes the expression of 699 genes in milk cells. Some of the downregulated genes are related to milk fat (ACACA, FASN, SCD, BTN1A1, and XDH) and protein (CSN1S1, CSN1S2, CSN3, and LALBA) synthesis. 
Furthermore, BCL2L1 (anti-apoptotic), and AKT1 (cell survival) genes are downregulated by HS, whereas BAX (apoptotic) gene is upregulated by HS. Taken together, the negative effects of HS on milk production might be explained by inhibiting mammary synthetic capacity as well as by increasing mammary cell death. In addition, cathepsin genes (CTSB, CTSD, CTSS, and CTSZ) are upregulated, which would result in greater casein degradation in milk produced from HS goats, which could explain the altered milk coagulation properties during cheese-making [80]. Recently, Salama et al. [87] reported lower phosphorylation level of 4E binding protein 1 (inhibitor of milk protein synthesis) in mammary cells under HS conditions $\left(42^{\circ} \mathrm{C}\right)$, which would diminish translation initiation and reduce milk protein synthesis. Additionally, HS results in the upregulation of several microRNAs related to cell growth arrest and apoptosis (miR-34a, miR-92a, miR-99, and miR-184) and oxidative stress (miR-141 and miR-200a). Interestingly, supplementation of HS mammary cells with methionine or arginine reverses most of the effects of HS occurring at the mRNA level. Both amino acids upregulate genes related to transcription and translation, insulin signalling, amino acid transport, and cell proliferation. The positive responses with methionine and arginine raise the possibility that supplementation with these amino acids might have a positive effect on mammary metabolism under HS conditions.

\subsection{Heat stress and intestinal cell integrity}

Heat stress has been shown to alter jejunal tight junction proteins in dairy cows, suggesting an impaired intestinal barrier function [88]. It is well known that a weak intestinal barrier allows for the paracellular transport of endotoxins, which results in the activation of the innate immune system and systemic inflammation. In fact, Koch et al. [88] showed that HS induces infiltration of myeloic origin and macrophage-like phenotype cells into the mucosa and submucosa of the jejunum as an immune response. In dairy goats, urine metabolomics revealed that HS increases the secretion of gut-derived uremic toxins or mammalian-microbial metabolites such as phenylacetate, phenylacetylglycine, phenylglyoxylate and trimethylamine $\mathrm{N}$-oxide [89]. These findings indicate that these toxins might leak through the gastrointestinal epithelium to the blood stream and excreted into urine in HS goats. Identifying these 
toxins in the urine of animals could be an interesting way of monitoring HS in small dairy ruminants and limit or anticipate consequences.

\subsection{Heat stress and the immune functions}

Besides the negative impact on milk production, HS impairs the immune system. Contreras-Jodar et al. [84] evaluated blood transcriptomics in dairy goats exposed to HS or TN conditions for 5 weeks. Compared to TN goats, chronic HS for 5 weeks resulted in 143 differentially expressed genes (55 upregulated and 88 downregulated). The functional gene analyses revealed that many biological pathways are downregulated by HS. These downregulated biological pathways are related to immune cell proliferation and migration (i.e. leukocyte transendothelial migration, cell adhesion molecules, and hematopoietic cell lineage), lipid metabolism (i.e. adipocyte and PPAR signalling), and tissue repair (i.e. arginine and proline metabolism and phagosome). On the other hand, HS upregulates pathways involved in immune cell death (i.e. pyrimidine metabolism, purine metabolism, cytochrome P450, and RNA transport). Overall, results from blood transcriptomics indicate that HS compromises both innate and adaptive immune responses in dairy goats, which would make HS goats more prone to infection.

Regarding the mammary gland during HS, available data indicates that HS might compromise the mammary immune status. Thompson et al. [90] reported that cows without cooling during the dry period have higher incidence of mastitis in the next lactation. However, limited information is available on the changes in the mammary gland metabolome during an infection under controlled HS conditions. In a recent work, Salama et al. [91] used metabolomics to compare milk from healthy goats and goats challenged with an intramammary administration of lipopolysaccharide (LPS), cell wall components from gram-negative bacteria which are commonly used to mimic mastitis caused by this type of bacteria [92,93]. Metabolomics of milk produced from TN and HS with and without LPS administration in the udder revealed different putative inflammation markers that include choline, phosphocholine, Nacetylcarbohydrates, L-lactate and B-hydroxybutyrate. However, the importance of these markers varied between TN and HS indicating different mammary immune response. 
As shown in Fig. 4, the use of omics techniques has demonstrated that HS impacts dairy goats at different levels. The immune system is negatively affected due to decreased haematopoiesis and leukocyte diapedesis. In addition, HS results in the disruption of lipid metabolism of immune cells, which would affect their functionality. Using urine metabolomics, various markers of leaky gut are detected, and these markers are related to the over-excretion of gut-derived toxic compounds generated by the harmful gastrointestinal microbiota. At the level of mammary gland, HS results in significant changes in the transcriptomic profile that include but not limited to the downregulation of milk fat and protein synthesis genes, and the upregulation of genes related to proteolysis and cell death. Furthermore, milk metabolomics showed that the inflammatory response to simulated infection is delayed by HS, decresing the ability to combat pathogens. . These factors demonstrate how omics can greatly benefit animal science, specifically in the tropical and subtropical contexts where HS is one of the most pressing problems. Because HS occurs in varying intensities, knowing how the animals respond physiologically is of paramount importance. This information allows the characterization of tolerant and susceptible breeds, which would lead the producers to reduce costs related to animal health and improve productivity. Such an approach, of studying adapted breeds, has been carried out for other topics such as seasonal weight loss. 


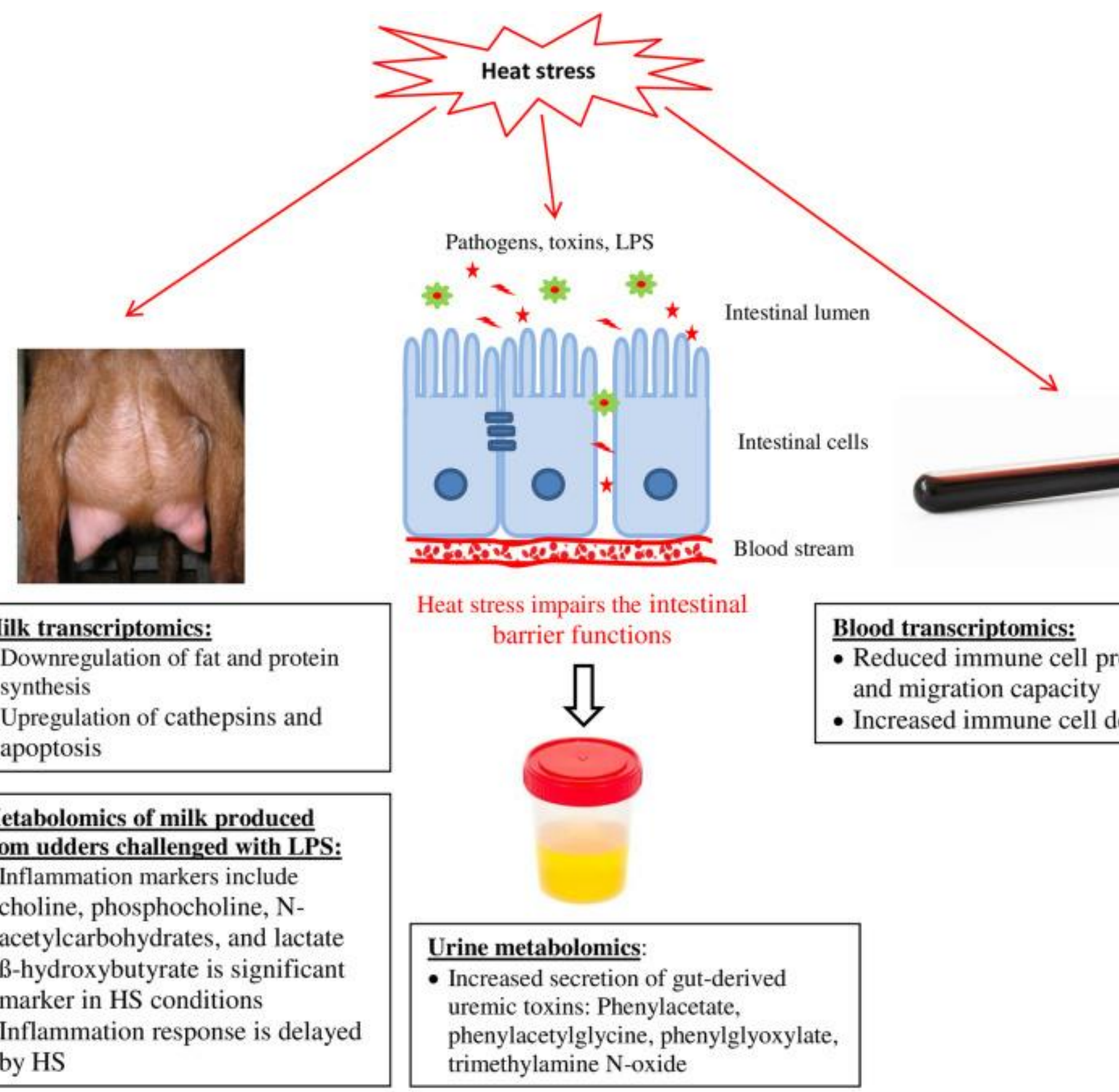

1. Download : Download high-res image (509KB)

2. Download : Download full-size image

Fig. 4. Application of different omics tools (transcriptomics and metabolomics) to evaluate the impact of heat stress on dairy goats.

\section{Seasonal weight loss in small ruminants: an omics approach}


Seasonal weight loss (SWL) is one of the most pressing issues in animal production in the tropics and the Mediterranean. Indeed, in these regions long dry seasons lead to poor pasture availability, both from a quantitative and qualitative perspectives, ultimately leading to SWL, that in turn has negative significant effects on animal productivity and health, as we have demonstrated for instance in Southern Africa [94] and the Canary Islands (Spain) [95]. To counter SWL, farmers may either supplement their animals, which is something difficult to conduct in remote regions, or they may choose to use breeds that are naturally adapted to such constraint. The use of omics, particularly proteomics, to study how small ruminants cope with SWL has been the focus of research over the last 20 years. We have been focusing on two major lines: meat producing sheep and dairy goats (Fig. 5).

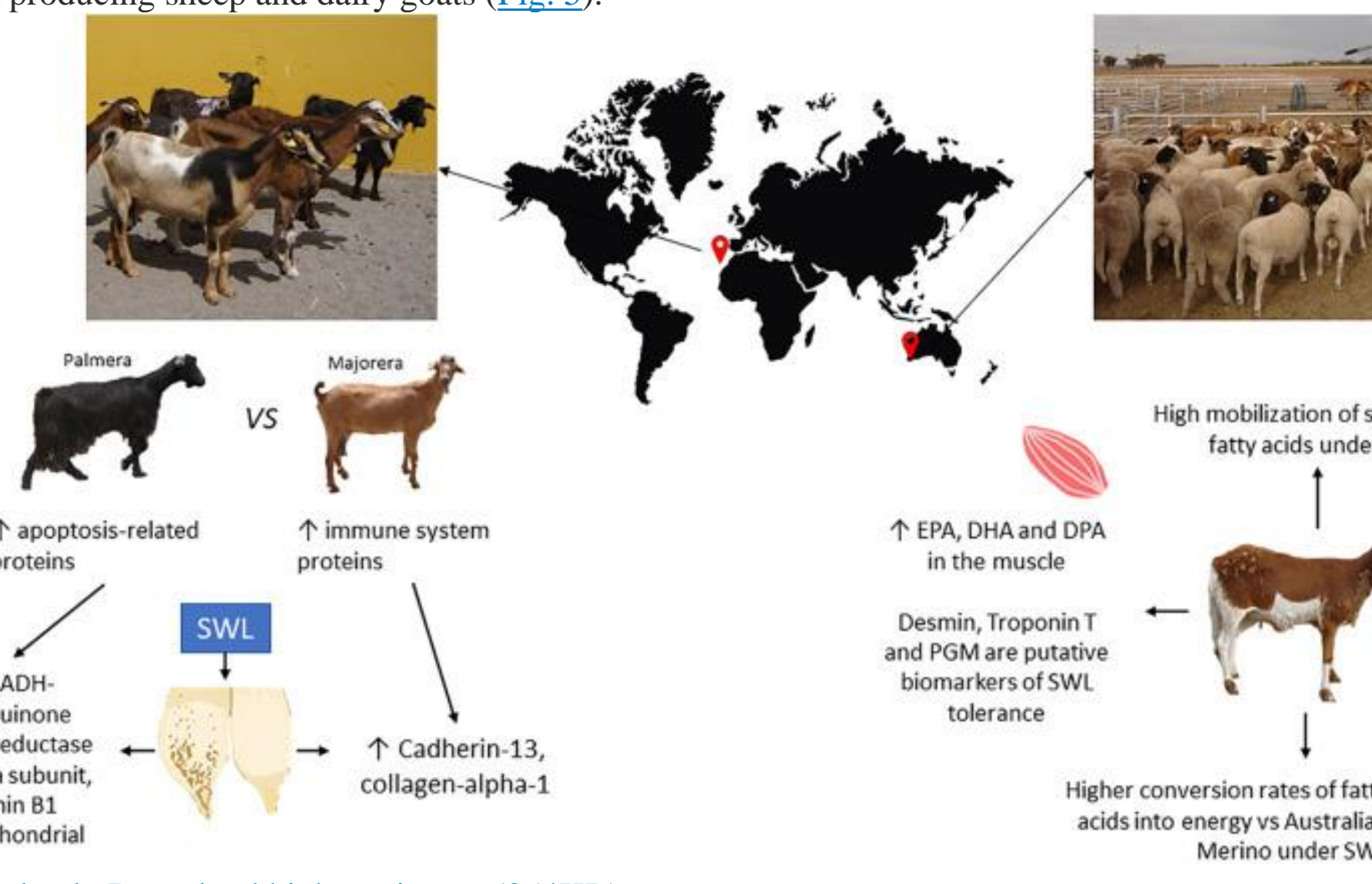

1. Download : Download high-res image (354KB)

2. Download : Download full-size image

Fig. 5. Summary of results from various omics approaches performed in Australia and the Canary Islands (Spain) to study seasonal weight loss (SWL) in small ruminants

\subsection{Sheep production studies in Australia}


The Damara is a fat-tailed breed from Southern Africa that is considered naturally adapted to SWL [96]. The breed has been imported to Australia where it has been used in extensive production systems in semi-arid regions. We have characterized the growth and carcass traits of Damara lambs in comparison to that of Merino and Dorper lambs $[97,98]$ under control and restricted growth conditions. The analysis also included a fatty acid profiling of the fat tailed Damara breed that noticed for the first time the accumulation in Damara tissues of branched chained FAs [99], a unique feature among ovine breeds. A detailed fatty acid profiling of the muscle tissues in the three breeds [100] was also conducted and results revealed several differences between Damaras and the other two breeds, namely a higher concentration of PUFA, which can be related to being a fat-tailed breed. Even in restricted feeding conditions, this breed revealed the highest levels compared to Merino and Dorper sheep respectively, of linoleic acid $(+31 \%$ and $+28 \%)$, linolenic acid $(+97 \%$ and $+51 \%)$, eicosapentaenoic acid (EPA) (+65\% and $+37 \%)$, docosapentanenoic acid (DPA) (+31\% Merino) and docosahexaenoic acid (DHA) (+63\% and $+77 \%)$. EPA, DPA and DHA are three omega-3 FAs, with described beneficial characteristics. Overall results suggest that Damara rams have a unique lipid metabolism. Later, we have used proteomics to study muscle metabolism and tolerance to SWL. We started with a 2DE approach [101] that lead to the establishment of the first putative markers of tolerance to SWL in the ovine muscle: Desmin, Troponin T, Phosphoglucomutase and the Histidine Triad nucleotide-binding protein 1. At a later stage, we have also conducted an approach using label-free proteomics [102] that led to further markers of tolerance to SWL in the ovine muscle. In total, authors identified 668 proteins of the sheep proteome, one of the most complete characterizations of the ovine skeletal muscle profile to date. Authors demonstrated that additional proteins are affected by restricted nutritional conditions: ferritin heavy chain; immunoglobulin V lambda chain; transgelin; fatty acid synthase; glutathione S-transferase A2; dihydrodiol dehydrogenase 3-like. More recently, we have also used proteomics to study the mechanisms of adaptation to SWL at the level of the hepatic metabolism. Again, we have used two approaches: one gel based focusing on the mitochondrial proteome [103] and one label-free focusing on the whole tissue [104]. The first led to the identification of a total of 50 proteins with seven changing significantly in abundance. Specific abundance patterns of corticosteroid and inflammatory response-associated 
proteins such as annexin and glutamate dehydrogenase suggested that the Damara has an unusual inflammation response when subjected to SWL in addition to its unique metabolism. All significant proteins warrant further study; Annexin in particular shows promise as a potentially useful biomarker. The second approach confirmed that the Damara has adapted to nutritional stress by mobilizing stored FAs within adipose tissue and converting them to energy more efficiently than the Merino. The latter had an overabundance pattern primarily directed to protein synthesis pathways. Several proteins were furthermore identified and validated and can be used as a basis for marker selection towards tolerance to nutritional stress. We have also used NMRspectroscopy metabolomics [105] to study the metabolic changes in the liver and muscle in these three breeds. Interestingly, the Dorper restricted group showed few changes in both tissues, suggesting higher tolerance to nutritional scarcity. The Merinos exhibited more differences between treatment groups. Major differences were related to fat and protein mobilization, and antioxidant activity. Between the Damara groups, the main differences were observed in amino acid composition in muscle and in energy-related pathways in the liver. Following this work, we focused exclusively on the amino acid profiles of muscle and liver of these lambs [106]. Damara lambs have higher capacity to mobilize muscle amino acids, particularly branch-chain amino acids, compared to other breeds during weight loss. Integration of omics results and with other data (e.g. amino acid profiles) on the same animals support the hypothesis that, Dorper and Damara breeds are more tolerant to SWL conditions and thus, more suitable breeds for harsh environmental (semi-arid) conditions.

\subsection{Dairy goat production studies in the Canary Islands}

We have also used omics to study the adaptation to SWL in dairy goats from the Canary Islands (Spain). This time, authors contrasted two breeds with different levels of adaptation to SWL: the Palmera (susceptible) and the Majorera (tolerant), at the level of the mammary gland secretory tissue. Authors started by studying production traits of both breeds [95] and later studied the blood biochemistry results [107]. Results pointed out to the existence of significant differences in creatinine, urea, free FAs, cholesterol, IGF-1 and T3 due to undernutrition. Furthermore, a principal 
component analysis (PCA) analysis revealed that animals submitted to undernutrition could be distinguished from the control groups, with the formation of three separate clusters (Palmera individuals after 22 days of undernutrition; Majorera individuals after 22 days of undernutrition and animals assigned to control conditions), highlighting different responses of the two breeds to undernutrition. We later used NMR-spectroscopy metabolomics [108] to study the differences between breeds. This comparison included milk in addition to the mammary gland secretory tissue.

Profiling analysis has led to the identification of 46 metabolites in the aqueous extract of the mammary gland. Lactose, glutamate, glycine and lactate were found to be the most abundant. Analysis of milk serum allowed the identification of 50 metabolites, the most abundant being lactose, citrate and creatine. Significant differences were observed, in mammary gland biopsies and milk serum, between control and restrictedfed groups in both breeds, albeit with no differences between the breeds. Variations seem to be related to metabolism adaptation to the low-energy diet and are indicative of breed-specific microflora. Milk serum showed more metabolites varying between control and restricted groups, than the mammary gland. The Majorera breed also showed more variations than the Palmera breed in milk samples, which could be an indication of a prompt adaptation to SWL by the Majorera breed. The study was completed with a label free [109] and a mitochondrial [110] proteomics analysis. The first enabled the identification of over 1000 proteins, of which 96 showed differential expression between two of the groups within studied comparisons. Majorera breed showed higher expression of immune system related proteins. In contrast, Palmera breed showed higher expression of proteins related to apoptosis. Results indicate that the two goat breeds have a distinct metabolism reaction to SWL, and that proteins related to the immune system and apoptosis such as cadherin-13, collagen alpha-1, nidogen-2, clusterin and protein s100-A8 could be considered putative candidates as markers of tolerance to SWL. The second approach further led to the identification of different proteins of relevance to SWL tolerance. These included NADH-ubiquinone oxidoreductase $75 \mathrm{kDa}$ subunit and lamin B1 mitochondrial (upregulated in the Palmera breed), Guanine nucleotide-binding protein $\mathrm{G}(\mathrm{I}) / \mathrm{G}(\mathrm{S}) / \mathrm{G}(\mathrm{T})$ subunit beta-2 (upregulated in the Majorera breed) and cytochrome b-c1 complex subunit 1, mitochondrial and Chain D, Bovine F1-C8 Sub-Complex Of Atp Synthase (downregulated in the Majorera breed) as a consequence of weight loss. 
These above-mentioned results undoubtedly show the prominence of omics approaches and Systems Biology in the establishment and the discovery of markers of tolerance to SWL, overall contributing to bypass SWL-derived problems in the framework of animal production systems in the tropics and the Mediterranean. Similarly, these approaches can also be used to study other a vast array of subjects within the animal science field, such as susceptibility to a disease and HS, as previously mentioned.

\section{Omics and colostrum nutrition}

Colostrum, the first secretion of the mammary gland postpartum, is the first source of nutrients (e.g. fat, lactose, vitamins, and minerals) for newborn mammals [111]. Colostrum is different from mature milk as it has higher protein and fat content. The higher protein content is mostly associated with increased immunoglobulin (Ig) content. In ungulates, Igs are not effectively transferred through the placenta during gestation. Therefore, colostrum is the main source of Igs to these animal species at birth. The early provision of colostrum Igs to the neonate decreases the risk of disease until its own immune system develops [112]. Therefore, the relation between colostrum and newborn survival has been exhaustively characterized in many livestock species such as cows, sheep, goats and pigs [[113], [114], [115], [116]]. Additionally, colostrum contains a complex mixture of proteins that actively participate in the protection of the neonate against pathogens and other postpartum environmental challenges [4]. Because of the wide range of protein concentrations present in colostrum, the identification of the whole colostrum proteome is complex. Over the last years, increased sensitivity and accessibility of several omics technologies (i.e. proteomics, transcriptomics and metabolomics) have allowed important advances in the field of livestock science. In this area, omics technologies have contributed to increase the understanding of the different physiological and biological processes regarding colostrogenesis and the importance of colostrum in newborn ungulates. Advanced and more sensitive proteomics approaches have provided crucial information about proteins present in colostrum from goats and sheep, especially those defined as low abundance proteins $[117, \underline{118}]$. Differences in the colostrum proteome of both species suggest that the use of colostrum replacer or 
colostrum from other species may not ensure a correct passive immune transfer to the offspring. Furthermore, these studies also showed that not only the blood Igs concentrations are increased in newborn lambs after colostrum feeding, but also several other immune proteins (i.e. fibrinogen, serum amyloid A, apolipoprotein AIV, among others). Similar studies about the differences between colostrum and milk proteomes have been performed also in dairy cows [[119], [120], [121]] and sows $[122,123]$.

Metabolomics have also provided novel information about the differences between colostrum and milk as well as the physiological changes in newborn livestock species caused by colostrum intake. As described by Curtasu et al. [124], metabolites involved in the metabolism and transport of FAs such as L-acetylcarnitine and 2metylbutyroylcarnitine, or metabolites such as glycerophosphocholine and choline are highly concentrated in colostrum compared to milk. In a similar study performed in dairy cows, Qi et al. [125] showed increased concentrations of leucine, cattle, glycocholic acid, acetoacetic acid, and uridine in colostrum compared to milk. However, these authors also described decreased concentrations of several metabolites including glutamate, ornithine, uric acid, stearidonic acid and citric acid in colostrum compared to milk. Most of these differences were related to processes such as the aminoacyl-tRNA biosynthesis, alanine, aspartate, glutamate, and butanoate metabolism, the citrate cycle, and the histidine metabolic pathway. These findings were in agreement with those from Zhao et al. [126] who observed increased concentrations of blood metabolites such as choline, tyrosine, glutamate, phenylalanine, valine and glutamate in calves fed with colostrum compared to those fed with milk after birth.

Transcriptomics studies have been also performed to complete the whole picture about colostrum characterization and its effect on newborn livestock species. Morrin et al. [127] studied the modulation capacity of bovine cow colostrum on human intestinal epithelial cells during increased commensal colonisation. These authors observed that the epithelial cells treated with cow colostrum had increased glycosylation activity which in turn may facilitate the adherence of different bacteria such bifidobacteria. Although this study was performed in in vitro conditions on human epithelial cells, similar results can be expected to occur in dairy calves after colostrum feeding. 
Besides the above-mentioned omics technologies have increased enormously the knowledge about colostrum and its impact of animal health status, more studies will be necessary to obtain deeper and clearer overview of the diverse processes that take place during colostrogenesis, colostrum secretion, intestinal colostrum absorption, and, finally, on the newborn immune system development. The continuous development of new and more sensitive proteomics, metabolomics and transcriptomics techniques will allow the identification of very low abundant components in tissues such as the mammary gland, the placenta or the intestine; and in fluids such as colostrum, milk or blood plasma. It is a matter of time until these components can be studied and related with other animal production issues, effectively complementing existing knowledge and pushing its boundaries.

\section{Omics and rumen microbiota}

The rumen microbial ecosystem is a complex anaerobic environment inhabited by bacteria, protozoa, fungi, methanogenic archaea, and bacteriophages [128], in which the core community is composed of poorly characterized microbes [129]. Nevertheless, rumen microbiota is known specialized in converting complex fibrous substrates into fermentation products that, with the microbial biomass, are utilized by ruminants for supporting their maintenance, growth, and lactation $[127,130]$. In developing countries located in the tropics, there are areas with high botanical diversity. In those areas, ruminants may play an important role in transforming those cellulosic plant materials into valuable sources of animal protein for human consumption [[131], [132], [133]]. Nevertheless, in the tropical regions besides lowquality roughages, most ruminants are fed on agricultural crop-residues and agroindustrial by-products often containing high levels of lignocellulosic materials, and low levels of good-quality protein. In addition, animal productivity is mainly limited by long dry seasons with a prevailing high temperature, and less feed available $[134,135]$. Therefore, manipulation of the ruminal microbiome to improve the utilisation of tropical forages and maximise ruminant productivity whilst minimising detrimental environmental outputs such as methane emissions are some of the most important research priorities regarding ruminant production in the tropics and subtropics. 
The characterization of rumen microbiota based on sequencing target regions of the 16S ribosomal RNA gene has been widely used. This approach provides information about the rumen microbial community but no information about their function [130]. However, the advances in the bioinformatics tools and omic technologies such as metagenomics, transcriptomics, metaproteomics, and metabolomics, allows a deeper insight into the rumen microbial ecology, particularly on the symbiotic host-microbe relationship and the impact of nutritional strategies on the animal performance [130]. Metagenomics allows the evaluation of both the diversity and the potential functional capacity of the microbiome, while metatranscriptomics can provide insight into the actual function of microbiomes via gene expression [128]. In addition to metatranscriptomics, the combination of metaproteomics and metabolomics can give information about the identification of the active microbial community. In addition, they inform on differently expressed metabolic pathways by accessing the proteins expressed and the metabolites produced through NMR- or MS-based methods [136]. Although next-generating sequencing methods and functional metagenomics are being now used to study the rumen microbiome in animals from tropical regions, integration the results with other meta-omics is still lacking.

The complex relationship between ruminant and rumen-dwelling microbiota has been studied for years in efforts to identify those microorganisms and their functional contributions to the host's energy requirements [137]. Henderson et al [129] examined the core rumen microbiota from ruminants in different regions of the world by sequencing regions of bacterial and archaeal 16S rRNA genes and ciliate protozoal $18 \mathrm{~S}$ rRNA genes, and found that the variability of rumen microorganisms is highly related to ruminant species, diet and geographical location. Thus, both the rumen microbiome and dietary nutrient utilization are expected to differ between ruminants from the tropics and temperate regions. Using omics to understand and gather more knowledge on this complex issue would undoubtedly benefit production systems. The ruminant species in the tropics include bovine, caprine and ovine, and their microbial communities have been evaluated using omics technologies, with results revealing that some taxa are commonly found in some ruminant species but inexistent in others [129,138]. Jami and Mizrahi [139] evaluated the composition and similarity of the microbiota of dairy cows and observed that there was a core rumen microbiota shared by all individuals. Notwithstanding, there were a large number of operational 
taxonomic units (OTUs) that are not shared by all animals despite the use of an equal diet, sampling procedures and experimental conditions. These authors also noted that while a large number of species were not shared by all cows, there was a high phylogenetic similarity between the communities [139].

In many regions of the tropics, unlike temperate countries, the ruminant diet is based on low-quality roughages [[140], [141], [142], [143], [1441], thus it is essential to understand which enzymes are responsible for the degradation of the dietary fibre and which are the main microorganisms that synthesize them $[142,143,145]$. Many studies have elucidated the degradation of fibrous carbohydrates by using omic technologies and on how diet influences methane production in the rumen [142,[146], [147], [148]]. Research results have shown a similarity between enzymes acting on the degradation of fibrous carbohydrates in the rumen $[\underline{145}, \underline{149}, \underline{150]}$. In Brazil, Lopes et al [145] using phylogenetic profiling analysis and shotgun-based sequencing, identified the Bacteroidetes or Firmicutes as the dominant phyla in the sheep rumen microbiome, followed by Proteobacteria, which were similar to those described in other studies [129]. These authors also using metagenomics data identified a set of potential carbohydrate-active enzymes in the rumen [145]. The rumen virome is much less studied, but in Australia, Ross et al [151] studied bacteriophages in dairy cows and reported a broad diversity of viruses between animals; however, cohabiting animals had a more similar virome sequencing profile than those which did not inhabit the same region. Recently, the rumen virome of sheep and goats from Kenya was also studied using metagenomics, but results showed significant contaminations with background DNA (i.e. bacterial and eukaryotic), highlighting that improvements in the viral DNA enrichment and isolation protocols are still needed [152].

As can be seen in Table 2, several studies in tropical countries on the rumen microbiome using 16S rRNA gene sequencing, metagenomics or transcriptomics have been published. Those studies are focused on how the rumen microbial community of different animal species degrades high-fibre feedstuffs, with a greater predominance of African, Asian and American countries. On the other hand, there is concern about environmental issues, e.g., ruminal methane production, which derives mostly from roughage fermentation. This is especially true in Australia and Brazil, where most ruminants are reared extensively, on C4 grass pastures [153]. The diversity of 
feedstuffs used in ruminant diets in the tropics also drives researchers, mainly in Asia, to determine which microorganisms are present in the rumen, and how feed components, geographical location and species influence microbial diversity.

Table 2. Examples of studies on the rumen microbiome using 16S rRNA gene sequencing, metagenomics or transcriptomics in tropical countries.

\begin{tabular}{|c|c|c|}
\hline Study & Countries & Authors \\
\hline $\begin{array}{l}\text { Rumen microbial enzymes that } \\
\text { degrade high-fiber feedstuffs }\end{array}$ & $\begin{array}{l}\text { South Africa; Saudi Arabia; } \\
\text { Brazil; India; Israel; Mexico }\end{array}$ & {$[145,[148],[149],[150],[154],[155],[156]]$} \\
\hline $\begin{array}{l}\text { Microbial community of different } \\
\text { ruminant species }\end{array}$ & $\begin{array}{l}\text { Australia; Colombia; Israel; } \\
\text { India; Kenya }\end{array}$ & {$[\underline{139}, \underline{140}, \underline{151}, \underline{152}, \underline{157}, \underline{158]}$} \\
\hline $\begin{array}{l}\text { Influence of diet on the microbial } \\
\text { community }\end{array}$ & $\begin{array}{l}\text { Australia; China; India; } \\
\text { Mexico }\end{array}$ & {$[141, \underline{146}, \underline{151,[159],[160],[161]]}$} \\
\hline $\begin{array}{l}\text { Influence of diet on the methane } \\
\text { production }\end{array}$ & Australia; Brazil; China; Índia & {$[\underline{142}, \underline{162}, \underline{163]}$} \\
\hline $\begin{array}{l}\text { Influence of geographical location } \\
\text { on the microbial community }\end{array}$ & Australia; Brazil; China & {$[\underline{137}, \underline{164}, \underline{165}]$} \\
\hline \multirow{7}{*}{\multicolumn{3}{|c|}{$\begin{array}{l}\text { Metaproteomics can be used to characterise the functional activity of the microbial } \\
\text { community [166]. Proteins give us the capacity to do taxonomic analysis based on the } \\
\text { alignment of their amino acid sequence, allowing the link between taxa and function } \\
{[167] \text {, including the identification of the active microbial expressed metabolic }} \\
\text { pathways [132]. Nevertheless, metaproteomics applied to rumen digesta samples can } \\
\text { be very challenging because the rumen can contain high levels of plant secondary } \\
\text { compounds, such as tannins, that complex with proteins and interfere with extraction } \\
\text { and purification procedures [164]. Thus, due to several limitations, metaproteome } \\
\text { studies applied to understand the composition and function of the ruminal microbiota } \\
\text { are scarce. }\end{array}$}} \\
\hline & & \\
\hline & & \\
\hline & & \\
\hline & & \\
\hline & & \\
\hline & & \\
\hline \multirow{5}{*}{\multicolumn{3}{|c|}{$\begin{array}{l}\text { The first description of the ruminal proteome was made by Deusch and Seifert [165] } \\
\text { with the identification of around } 2000 \text { proteins associated with the rumen microbial } \\
\text { community. More recently, Snelling and Wallace [164] studied the rumen microbial } \\
\text { composition of bovine and ovine subjects and, in similarity with other metagenomics } \\
\text { studies, the enzymes involved in glycolysis, predominantly from }\end{array}$}} \\
\hline & & \\
\hline & & \\
\hline & & \\
\hline & & \\
\hline \multicolumn{3}{|c|}{ the Firmicutes and Bacteroidetes phyla, dominated the prokaryotic metaproteome. } \\
\hline ese authors also found th & & \\
\hline
\end{tabular}


the characterization of the metaproteome of ruminants in tropical environments, which could be particularly interesting since a large proportion of the global ruminant population is located in these regions.

The application of metabolomics to study the rumen microbial activity is also emerging, and its importance is linked to the fact that it can provide important biochemical insights into the role of host-diet interactions in the rumen. Indeed, during microbial fermentation and digestion of feedstuffs, several metabolites such as volatile FAs, organic acids, sugars, amino acids, amines, or FAs, are produced in the rumen. These metabolites are then used by the microbes for their proliferation, and further absorbed and utilized for meat and milk production, as well as for body maintenance [166]. The majority of the studies on rumen fluid metabolomics have investigated the increased proportion of concentrate/grain in a diet compared with roughage $[157, \underline{167}, \underline{168]}$. Zhang et al [157] found that high concentrate diets significantly increased the concentration of bacterial degradation products and some toxic compounds, including LPS, biogenic amines, or ethanolamine. In another study conducted in China, Zhao et al [169] showed that different types of roughages significantly influenced the ruminal microbial metabolome of dairy cows, in particular in the production of organic acids, amines, and amino acids. However, because metabolomics cannot directly link metabolites to a microbial species, associations with changes in microbial relative abundance through microbial profiling, metatranscriptomic or metaproteomic are required [133].

The challenge in the future would be integrating omics data to allow the construction of rumen specific microbial metabolic models [137] able to predict and generate ruminal environments and their occurring metabolic processes in order to drive improvements in animal productivity and environmental sustainability.

\section{Omics in tropical veterinary medicine: case studies}

Animal production in the tropics and the sub-tropics deals with a vast array of infectious diseases, external and internal parasitism and metabolic disease. The topic is very broad and vast. In order to be adequately addressed, several reviews would have to be dedicated to the topic. In this review, we have focused on two examples that are very characteristic and a clear example of animal health in these regions; tick- 
borne diseases (TBD) and gastrointestinal parasites. In this section, we will therefore focus on two case-studies where omics tools have been successfully applied. Fig. $\underline{6}$ sums some findings that have been achieved in these areas using omics.
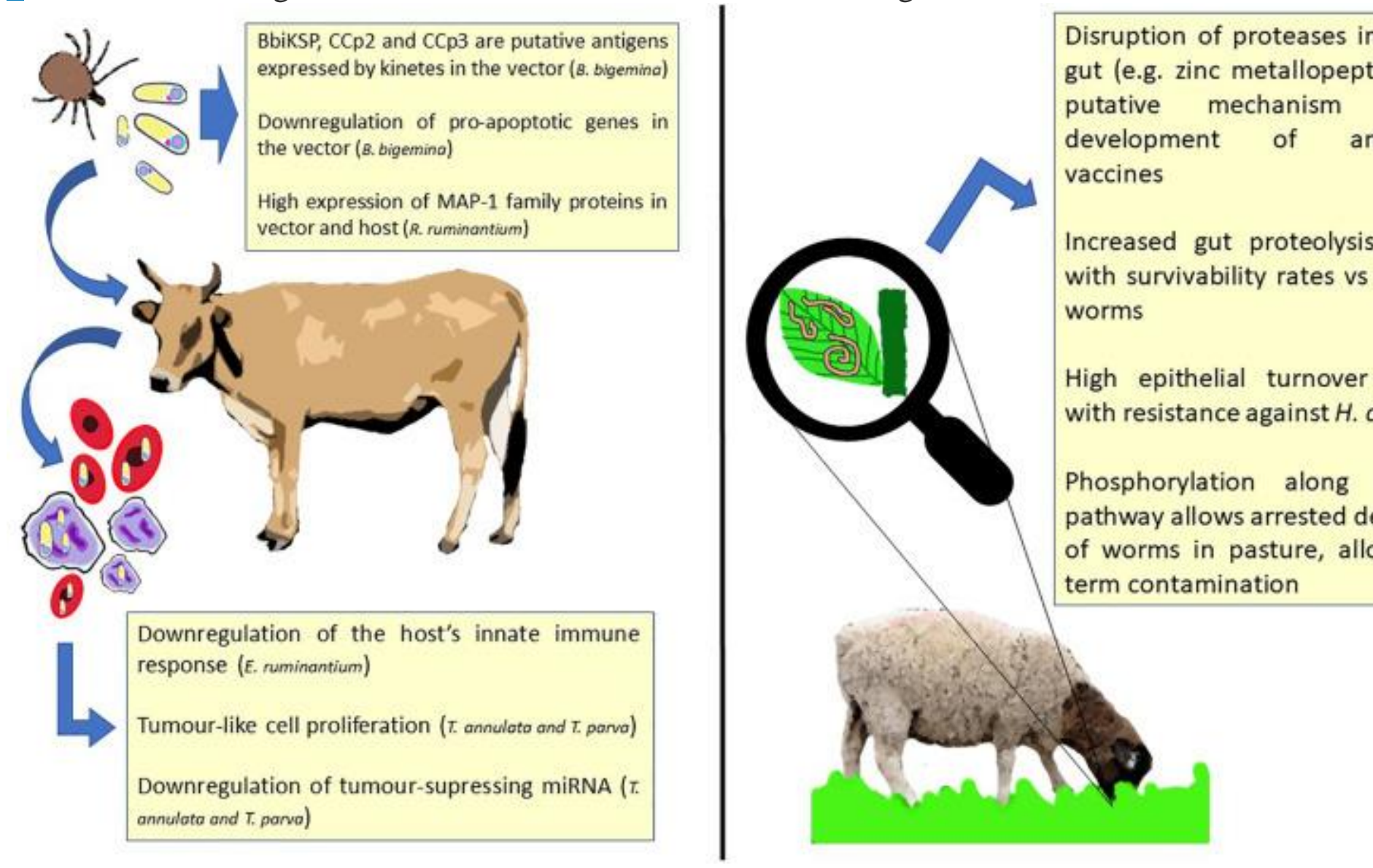

1. Download : Download high-res image (491KB)

2. Download : Download full-size image

Fig. 6. Recent findings obtained using omics in tick-borne diseases (left) and Haemonchus contortus biology (right).

\subsection{Tick-borne diseases and omics: studying the host-vector-parasite triumvirate}

In tropical and sub-tropical regions, farmers frequently have to cope with TBD. These diseases are caused by intracellular parasites that infect the ruminant host via a tick. The losses that derive from TBD are immense, impairing the economic viability of farms in vast regions as well as negatively affecting food supply chains. This is particularly serious in rural areas. There are four major groups of such diseases in livestock: theileriosis, babesiosis, anaplasmosis and cowdriosis. To deal with them, 
farmers can resort to either chemical treatments against ticks (e.g. dipping) or vaccines (i.e. tick or pathogen specific). The former could generate chemical-resistant ticks (i.e. vectors) as well as leave residues in edible products (e.g. milk and meat). In turn, many vaccines to treat these ailments are live (e.g. blood derived or attenuated) and require refrigeration, have short shelf lives, could potentially transmit other diseases or revert to virulence [174].

In 2012, Marcelino et al. [174] published a comprehensive review on the contribution of proteomics and other post-genomic tools (i.e. transcriptomics and metabolomics) to understand the interactions of the host-parasite and vector-parasite, which contribute towards the development of improved vaccines. Since then, several advancements have been achieved in studying these diseases.

Heartwater disease is a TBD transmitted by Amblyomma ticks. It is caused by the gram-negative bacteria Ehrlichia ruminantium, which causes mortality rates that reach 90\% in sub-Saharan Africa and in the Caribbean [175]. This bacterium has high genetic variability, with strains with different levels of virulence, which limits vaccine efficacy. Marcelino et al. [176] compared the proteome of two strains: attenuated and virulent. The latter has higher abundance of proteins involved in energy conversion and production, which the authors related with energy requirements of virulent processes. Membrane MAP-1 (Major Antigenic Protein) family proteins were the most abundantly identified in the E. ruminantium proteome, which at the time, required further studies to understand their role. Additionally, AnkA protein was highly abundant in the virulent strain. This protein alters the host's gene expression, allowing the manipulation of the inflammatory response from the host. A contemporary study found that the MAP-1 family proteins should be a priority target for the development of a vaccine, since they are involved in the adaptation of the parasite to the host and vector [177]. Other proteins such as the Type IV Secretion System (T4SS) proteins should also be targeted, since they transport bacterial DNA and protein to the host, to interfere with host metabolism. Later, these same genes were reported to be highly expressed in the E. ruminantium Gardel strain and the authors suggested that these MAP-1 proteins induce non-protective immune response [178]. A transcriptome study, of sheep peripheral blood mononuclear cell (PBMC) cells, has reported that this bacterium causes the downregulation of the innate immune response in the first day post-infection. The expression of genes related to this 
response reaches a peak in the sixth day, with genes such as toll-like receptors (TLR), TLR-2 and TLR-4, which are known as receptors of bacterial pathogens. Moreover, there was a higher expression of cytokines during a feverish state [179]. Finally, a recent study has reported that the infection of vector and host cells alike is accompanied by an increased expression of MAP-1 genes. This was found to be related to the induction of non-protective antibodies by the MAP-1 proteins, a mechanism that protects the parasite from the host response [180]. Babesiosis is a TBD caused by parasites from the Babesia genus, such as $B$. bigemina and B. bovis. They infect erythrocytes, causing anaemia, fever and even death. In cattle, both of these species are the main agent of the disease, which is transmited by Rhipicephalus microplus and R. annulatus ticks [181]. For this TBD, research is focused in the study of vector-pathogen interactions to develop an anti-tick vaccine, since there is not much literature available on the pathogen-host interaction. For this purpose, Bohaliga et al. [182] have suggested three genes (BbiKSP, CCp2 and $\mathrm{CCp} 3$ ) expressed by B. bigemina kinetes as putative antigens to develop a vaccine that inhibits the development of the pathogen in the vector, thus preventing host infection. Kinetes infect the female tick ovaries, perpetuating the infection by spreading on to the offspring. Johnson et al. [183] found that the BBOV_I002220 gene was highly expressed by B. bovis kinetes. By having the female tick feeding on blood with kinete-specific antibodies, the development and dissemination of Babesia pathogens could be stopped. In addition, the exposure of ticks to $B$. bigemina downregulates the transcription of dapk-1 gene (pro-apoptotic kinase) in the salivary glands. This inhibition of apoptosis allows the maintenance of infection, increasing the chance of infecting the target-host [184]. Other authors found that ticks feeding on B. bovis infected calves have higher expression of several proteinases in the gut, a response of the immune system. Likewise, lipid metabolism genes, such as vitellogenin, were also upregulated, most likely due to the disruption of the infected erythrocytes that were ingested [184]. This information complements what was found for kinete gene and protein expression, allowing the comprehension of the biology behind Babesia pathogenicity. However, metabolomics studies are clearly lacking, which would undoubtedly improve the currently available knowledge. In addition, researchers have also been dedicating resources to further understand lesser known Babesia species such as B. orientalis [185], B. ovata [186] and B. 
divergens [187]. Further research would be expected in the next years, aiming at understanding these species that affect cattle, water buffalos and small ruminants alike.

In recent years, significant advancements were made in the study of anaplasmosis using omics approaches. This disease causes anaemia, fever, abortions and weight loss, often culminating in death [188]. In cattle, it is caused by Anaplasma marginale, a gram-negative bacteria that infects ruminant erythrocytes [189]. The genome sequence of different Mexican strains has been reported recently [188]. At the moment, there are not effective treatments for this disease. Most efforts are being directed at finding antigens to be used in an attenuated vaccine. Pierle et al. [190] used a transcriptomics approach to identify genes related with the slow growth phenotype, which allows immunization using attenuated vaccines. The authors found three metabolic pathways differentially expressed in slow growing A. marginale: translation, translation elongation and purine biosynthesis. These findings point towards the importance that nucleotide synthesis has, enabling the development of this pathogen. In the future, other approaches should also be considered, since it is well documented that attenuated vaccines could regress to virulence. Recently, other significant advancements have been made in small ruminant anaplasmosis, namely, the sequencing of the A. ovis genome isolated from goats [191]. This has also been done by other authors [192]. Albeit not as severe for small ruminants as it is for cattle, small ruminant anaplasmosis still causes significant losses when considering its wide dissemination. Therefore, having its genome sequenced lays the foundation for future studies using post-genomic tools to identify useful antigens.

Theileriosis has been widely studied in recent years. This TDB is a particular case, since it modulates the host's cell gene expression, causing tumour-like cell proliferation. It is endemic to Africa and China and is currently present in Southern European countries such as Portugal [193]. Theileria parva and T. annulata are the two main causative agents of this disease. These protozoa infect host's leukocytes, inducing cell transformation and metastasis. Authors have found that the bta-miR181a and bta-miR-181b (tumour supressing genes) are under expressed in infected cells, whilst simultaneously increasing expression of pro-oncogenic miRNA [194]. In a 1DE-MS/MS proteome study, Witschi et al. [195] have studied the proteome of $T$. annulata schizont, and found that the TCA cycle enzymes are not all expressed by this 
pathogen. The authors did not identify proteins related with the interaction between parasite-host. Later, using a more sensitive LC-MS/MS approach, other authors successfully identified SVSP and TashAT family proteins, which include TpMuguga_03g00882 protein which acts on the nucleus of the host, modifying gene expression. This disease is particularly complex and warrants further research to fully understand how it modifies gene expression, particularly now that it has been detected in small ruminants [196] in addition to cattle. Using post genomic tools to delve into post-translational modifications [197] and the mechanisms of N-glycosylation beyond genomics [198] should uncover exciting discoveries.

The above-mentioned studies are a clear example of how omics allow an in depth understanding of complex diseases. Heartwater for example is a serious disease that makes the insertion of more productive breeds in endemic areas unviable, compromising potential productivity in areas with food shortages. In addition, TBD are could easily enter unaffected regions where the vectors are already present, such as the USA [174]. The vaccines currently available are not fully effective. Hence, using proteomics and transcriptomics has allowed the scientific community to gather information that could potentially improve vaccine development and efficiency. Diseases such as anaplasmosis are lacking important details regarding parasite biology and scientists are only now scratching the surface. Lesser known diseases and emerging pathogen species should be considered in future research on TBD using omics approaches.

\subsection{Recent advances in Haemonchus contortus biology}

Helminthic parasites such as Haemonchus contortus cause massive losses in small ruminant production worldwide. This parasite feeds on the blood of its host, in the stomach (abomasum). It may cause anaemia and gastritis. It is transmitted orally, by the ingestion of contaminated pasture. Control of these parasites is commonly made with chemicals or drug administration to the host. Rising concerns regarding the contamination of edible products and reports of drug-resistant parasites have propelled the industry to seek viable alternatives for parasite control [199], in a very similar way to what we have reported previously for TBD. Using omics, scientists have recently made significant advances towards understanding $H$. contortus biology. 
The main alternative for drug application towards the treatment of gastrointestinal parasites such as $H$. contortus, are vaccines, although dietary manipulation has also been reported [200]. Specifically, some studies were published where the authors aim to find candidate antigens for vaccines aiming to disrupt the digestion of blood protein by the worm. Dicker et al. [201] identified candidate antigens common to both $H$. contortus and Mecistocirrus digitatus, a cattle parasite. These were proteins, such as glutamate dehydrogenase, zinc metallopeptidases are common to both parasites. This could allow the development of a polyvalent vaccine. In 2018, Sallé et al. [202] reported the mechanism of resistance of $H$. contortus male worms to Barbervax ${ }^{\circledR}$, a commercially available anti-helminth vaccine. This vaccine contains two protease fractions: H11 and H-gal-GP. These aim at disrupting the digestion of haemoglobin, which results in the decrease of eggs expelled by the host, ultimately reducing pasture contamination. Surviving worms increased the expression of cysteine peptidase, which increases proteolysis rates, counter-acting the effect of the vaccine in addition to possibly increase $\mathrm{IgG}$ degradation in the gut. Due to the high genetic variability of this parasite, having several targets in vaccines would be very important for vaccine development. Having ineffective vaccines could lead to resistant worms which would hinder parasite control in the long-term. Another approach has been carried out that would avoid this possibility: using resistant breeds or select towards resistance. Zhang et al. [203] reported that there is a strong relation between gene expression towards reorganization of the abomasum epithelial layer and resistance against $H$. contortus. This points out to the epithelial turnover being partly responsible for increased worm expulsion. In addition, the latter authors found that $20 \%$ of the genes differentially expressed infected resistant Merino sheep were related with extracellular exosomes, which are important organelles for antigen presentation during parasitic infections. Hence, vaccine development and breed selection could be regarded as the most viable alternatives to current widespread practices of chemical treatments. Moreover, selecting hardier breeds against gastrointestinal parasites in a similar way to what has been presented for sheep against SWL would warrant further studies. Omics applications could provide the solution to find resistance-granting pathways and molecular mechanisms for susceptibility. Parasite biology and host response have also been addressed. Recently, Wang et al. [204] have studied the phosphoproteome of H. contortus, throughout its development. 
The authors identified several phosphorilations along the IGF-1 signalling pathway, which could be related to the arrested development of the larvae during the L3 stage, during which they contaminate pasture. Arresting its development, gives the parasite the ability to contaminate the pasture and survive without a host for long periods. To evaluate host response and the effect of stress hormones during infection, Chen et al. [205] treated H. contortus worms with norepinephrine in vitro and made a proteome analysis of its secretome and body proteins. Hormone treatment significantly altered protein, fat and energy metabolism. Galectin expression increased. This is a mechanism of infection in which the worm releases this protein to inhibit host expression of IL-2, IL-4, INF- $\gamma$ and TNF $\alpha$. Protein-dissulphide isomerase increased in the body and secretome, which protects the worm cells from oxidative stress and maintains endoplasmatic reticulum redox homeostasis. In the host's PBMC, this hormone lowers expression of inflammatory response mediators such as IL-2. These studies are an example of the importance of omics-oriented approaches to answer complex questions and uncover new possibilities. From analysing breed resistance to evaluating the infection mechanism of $H$. contortus, omics results are allowing the development of very important practices to control this parasite. In the future, other approaches would also be useful, such as metabolomics, to complement the results found in transcriptomics and proteomics studies. Moreover, exploring the resistance of breeds against this parasite and focusing on the molecular mechanisms that allow improved resistance would surely improve reproduction programmes and further inform the farmers decision making.

\section{Conclusions and future perspectives}

Omics research in the tropics has the potential to benefit animal production in such countries. The challenges ahead are immense. Environmental changes could impair production conditions in already harsh regions, such as the ones mentioned for Australia. Areas where extensive agriculture is the norm would benefit from omics to understand how to modulate the rumen environment and take the most from the resources available. Further understanding on how colostrum components are absorbed by the young animal could help the reduction of early-life mortality. Furthermore, additional research is necessary to analyse the full extent of HS on milk 
and its derived products. The study and modulation of pathways related to HS tolerance would surely benefit the dairy industry. The use of omics to study the meat quality of less known species, such as the water buffalo (Bubalus bubalis), under different production systems would also be interesting. Finally, the study of the effect of nutritional strategies to improve animal performance on the various omics should uncover new possibilities.

However, there is yet a long way to optimize omics research in the tropical context. Omics research is heavily dependent on quality databases. The Zebu cattle is, to this date, without a properly composed database to explore, for instance, its proteome. This causes the researchers to use the database that is closer taxonomically to the studied species, as done before in a study with wild ruminants [206]. The same issue could rise from studying other uncommon tropical or sub-tropical species, such as the dromedary (Camelus dromedarius) or the yak (Bos grunniens), the water buffalo (Bubalus bubalis) or South American camelids (llama: Lama glama and alpaca Vicugna pacos).

Finally, and similarly to many areas of animal science, the application of omics is hindered by different factors that are very difficult to control. These include many variables. However, a limited number of analysed animals, a difficulty establishing adequate and representative control groups or the very access to omics technologies and state of the art omics platforms is still a major challenge. Therefore, it is of the utmost importance to propose a general experimental framework for reaching statistically robust and practically sound strategies for improving animal production via omics tools. In such a context, and given the heterogeneity of tropical domestic breeds, the establishment of a minimum experimental group size of 4-6 animals could be proposed. Regardless of the experimental design, one important aspect that needs to be taken into consideration by animal scientists using omics is the complimentary nature of the different omics. Indeed, an approach using transcriptomics, proteomics and metabolomics is always to be preferable when addressing a research topic such as those mentioned in this review. The access to state of the art omics platforms is also a major challenge, particularly given the high costs and expertise such platforms comprise. To circumvent such problems, scientific cooperation is the only possible answer. Despite all the difficulties and challenges, in the future, it is expectable to see a rising number of publications related to animal production in the tropics integrated 
with omics approaches. This would definitely help the industry to cope with the challenges ahead.

\section{Credit author statement}

All authors participated in writing this review paper. All authors read and agreed on the final version of the manuscript.

\section{Acknowledgements}

Authors DM Ribeiro and AM Almeida acknowledge funding from FCT - Fundação para a Ciência e a Tecnologia (Lisbon, Portugal) in the form of Research Center Programs LEAF (Linking Landscape, Environment, Agriculture and Food) ref. UID/AGR/04129 and the PhD grant (SFRH/BD/143992/2019) awarded to DM Ribeiro. Authors ACM Vítor and SP Alves acknowledge funding also from the FCT in the form of Research Center Program CIISA (Interdisciplinary Animal Health Research Center) ref. UID/CVT/276/2020, the research project PTDC/CALZOO/29654/2017 and the PhD grant (SFRH/BD/136609/2018) awarded to ACM Vítor.

\section{References}

L.E. Hernández-

Castellano, J.E. Nally, J. Lindahl, M. Wanapat, I.A. Alhidary, D. Fangueiro, D. Grace, M . Ratto, J.C. Bambou, A.M. de Almeida

Dairy science and health in the tropics: challenges and opportunities for the next decades

Trop. Anim. Health Prod., 51 (2019), pp. 1009-1017, 10.1007/s11250-019-01866-6

CrossRefView Record in ScopusGoogle Scholar

[2]

C. Gonzalez Fischer, D. Bilenca

Can we produce more beef without increasing its environmental impact? Argentina as a case study

Perspect. Ecol. Conserv. (2020), 10.1016/j.pecon.2019.12.002

Google Scholar

[3]

M. Te Pas, A. Hoekman, M. Smits 
Biomarkers as management tools for industries in the pork production chain

J. Chain Netw. Sci., 11 (2011), pp. 155-166, 10.3920/JCNS2011.Qpork6

View Record in ScopusGoogle Scholar

4

E. Bendixen, M. Danielsen, K. Hollung, E. Gianazza, I. Miller

Farm animal proteomics - a review

J. Proteome, 74 (2011), pp. 282-293, 10.1016/j.jprot.2010.11.005

ArticleDownload PDFView Record in ScopusGoogle Scholar

$$
\text { [5] }
$$

A.M. de Almeida, E. Bendixen

Pig proteomics: a review of a species in the crossroad between biomedical and food sciences

J. Proteome, 75 (2012), pp. 4296-4314, 10.1016/j.jprot.2012.04.010

ArticleDownload PDFView Record in ScopusGoogle Scholar

$$
\text { [6] }
$$

I. Miller, C. Rogel-Gaillard, D. Spina, L. Fontanesi, A. de Almeida

The rabbit as an experimental and production animal: from genomics to proteomics Curr. Protein Pept. Sci., 15 (2014), pp. 134-145, 10.2174/1389203715666140221115135 CrossRefView Record in ScopusGoogle Scholar

$$
\lceil 71
$$

E. Veiseth-Kent, A.M. de Almeida, B. Picard, K. Hollung

Proteomics in Skeletal Muscle Research

A.M. Almeida, D. Eckersal, I. Miller (Eds.), Proteomics Domest. Anim. from Farm to Syst. Biol, Springer International Publishing, Cham (2018), pp. 195-217, 10.1007/978-3319-69682-9_10

CrossRefView Record in ScopusGoogle Scholar

\section{[8]}

K. Hettinga, L. Zhang

Omics and systems biology: integration of production and omics data in systems biology, Proteomics Domest. Anim. from Farm to

Syst. Biol. (2018), pp. 463-485, 10.1007/978-3-319-69682-9_22

CrossRefView Record in ScopusGoogle Scholar

S.A. Goldansaz, A.C. Guo, T. Sajed, M.A. Steele, G.S. Plastow, D.S. Wishart

Livestock metabolomics and the livestock metabolome: a systematic review PLoS One, 12 (2017), pp. 1-26, 10.1371/journal.pone.0177675

Google Scholar

J.S. Osorio, M. Vailati-Riboni, A. Palladino, J. Luo, J.J. Loor

Application of nutrigenomics in small ruminants: lactation, growth, and beyond 
Small Rumin. Res., 154 (2017), pp. 29-44, 10.1016/j.smallrumres.2017.06.021

ArticleDownload PDF View Record in ScopusGoogle Scholar

E.M. Ibeagha-Awemu, X. Zhao

Epigenetic marks: regulators of livestock phenotypes and conceivable sources of missing variation in livestock improvement programs

Front. Genet., 6 (2015), pp. 1-17, 10.3389/fgene.2015.00302

Google Scholar

X. Liu, J. Yang, Q. Zhang, L. Jiang

Regulation of DNA methylation on EEF1D and RPL8 expression in cattle Genetica., 145 (2017), pp. 387-395, 10.1007/s10709-017-9974-X

CrossRefView Record in ScopusGoogle Scholar

O. González-Recio, M.A. Toro, A. Bach

Past, present, and future of epigenetics applied to livestock breeding

Front. Genet., 6 (2015), pp. 1-5, 10.3389/fgene.2015.00305

Google Scholar

M.E. Goddard, E. Whitelaw

The use of epigenetic phenomena for the improvement of sheep and cattle Front. Genet., 5 (2014), pp. 1-6, 10.3389/fgene.2014.00247

CrossRefGoogle Scholar

J.B.S. Ferraz, P.E. de Felício

Production systems - an example from Brazil

Meat Sci., 84 (2010), pp. 238-243, 10.1016/j.meatsci.2009.06.006

ArticleDownload PDFView Record in ScopusGoogle Scholar

E.K.F. Chan, S.H. Nagaraj, A. Reverter

The evolution of tropical adaptation: comparing taurine and zebu cattle Anim. Genet., 41 (2010), pp. 467-477, 10.1111/j.1365-2052.2010.02053.x 


\section{CrossRefView Record in ScopusGoogle Scholar}

G. Whipple, M. Koohmaraie, M.E. Dikeman, J.D. Crouse, M.C. Hunt, R.D. Klemm

Evaluation of attributes that affect longissimus muscle tenderness in Bos taurus and Bos indicus cattle

J. Anim. Sci., 68 (1990), pp. 2716-2728, 10.2527/1990.6892716x

CrossRefView Record in ScopusGoogle Scholar

P.E. Strydom, R.T. Naude, M.F. Smith, M.M. Scholtz, J.B. Van Wyk

Characterisation of indigenous African cattle breeds in relation to meat quality traits

Meat Sci., 55 (2000), pp. 79-88, 10.1016/S0309-1740(99)00128-X

ArticleDownload PDFView Record in ScopusGoogle Scholar

F. Monsón, C. Sañudo, I. Sierra

Influence of cattle breed and ageing time on textural meat quality

Meat Sci., 68 (2004), pp. 595-602, 10.1016/j.meatsci.2004.05.011

ArticleDownload PDFView Record in ScopusGoogle Scholar

X. Xie, Q. Meng, Z. Cui, L. Ren

Effect of cattle breed on meat quality, muscle fiber characteristics, lipid oxidation and fatty acids in China

Asian-Australasian J. Anim. Sci., 25 (2012), pp. 824-831, 10.5713/ajas.2011.11462

CrossRefView Record in ScopusGoogle Scholar

M.A. Elzo, D.D. Johnson, J.G. Wasdin, J.D. Driver 
Carcass and meat palatability breed differences and heterosis effects in an AngusBrahman multibreed population

Meat Sci., 90 (2012), pp. 87-92, 10.1016/j.meatsci.2011.06.010

ArticleDownload PDFView Record in ScopusGoogle Scholar

R.T.S. Rodrigues, M.L. Chizzotti, C.E. Vital, M.C. Baracat-

Pereira, E. Barros, K.C. Busato, R.A. Gomes, M.M. Ladeira, T.S. Martins

Differences in beef quality between Angus ( Bos taurus taurus ) and Nellore ( Bos taurus indicus ) cattle through a proteomic and phosphoproteomic approach PLoS One, 12 (2017), Article e0170294, 10.1371/journal.pone.0170294

CrossRefGoogle Scholar

A.S.C. Pereira, F. Baldi, R.D. Sainz, B.L. Utembergue, H.L.J. Chiaia, C.U. Magnabosco, F.R. Manicardi, F.R.C. Araujo, C.F. Guedes, R.C. Margarido, P.R. Leme, P.J.A. Sobral

Growth performance, and carcass and meat quality traits in progeny of Poll Nellore, Angus and Brahman sires under tropical conditions Anim. Prod. Sci., 55 (2015), pp. 1295-1302, 10.1071/AN13505

View Record in ScopusGoogle Scholar

L.K. Matukumalli, C.T. Lawley, R.D. Schnabel, J.F. Taylor, M.F. Allan, M.P. Heaton, J. O’Connell, S.S. Moore, T.P.L. Smith, T.S. Sonstegard, C.P. Van Tassell

Development and characterization of a high density SNP genotyping assay for cattle PLoS One, 4 (2009), 10.1371/journal.pone.0005350

Google Scholar

A.S.M. Cesar, L.C.A. Regitano, G.B. Mourão, R.R. Tullio, D.P.D. Lanna, R.T. Nassu, M. A. Mudado, P.S.N. Oliveira, M.L. do

Nascimento, A.S. Chaves, M.M. Alencar, T.S. Sonstegard, D.J. Garrick, J.M. Reecy, L.L. Coutinho

Genome-wide association study for intramuscular fat deposition and composition in Nellore cattle 
BMC Genet., 15 (2014), pp. 1-15, 10.1186/1471-2156-15-39

CrossRefView Record in ScopusGoogle Scholar

M.V.A. Lemos, H.L.J. Chiaia, M.P. Berton, F.L.B. Feitosa, C. Aboujaoud, G.M.F. Camar go, A.S.C. Pereira, L.G. Albuquerque, A.M. Ferrinho, L.F. Mueller, M.R. Mazalli, J.J.M. Furlan, R. Carvalheiro, D.M. Gordo, R. Tonussi, R. Espigolan, R.M.O. Silva, H.N. de Oliveira, S. Duckett, I. Aguilar, F. Baldi

Genome-wide association between single nucleotide polymorphisms with beef fatty acid profile in Nellore cattle using the single step procedure BMC Genomics, 17 (2016), pp. 1-16, 10.1186/s12864-016-2511-y CrossRefView Record in ScopusGoogle Scholar

P.C. Tizioto, J.E. Decker, J.F. Taylor, R.D. Schnabel, M.A. Mudadu, F.L. Silva, G.B. Mo urão, L.L. Coutinho, P. Tholon, T.S. Sonstegard, A.N. Rosa, M.M. Alencar, R.R. Tullio, S.R. Medeiros, R.T. Nassu, G.L.D. Feijó, L.O.C. Silva, R.A. Torres, F. Siqueira, R.H. Hi ga, L.C.A. Regitano

Genome scan for meat quality traits in nelore beef cattle

Physiol. Genomics, 45 (2013), pp. 1012-1020, 10.1152/physiolgenomics.00066.2013

CrossRefView Record in ScopusGoogle Scholar

A.F.B. Magalhães, G.M.F. De Camargo, G.A. Junior

Fernandes, D.G.M. Gordo, R.L. Tonussi, R.B. Costa, R. Espigolan, R.M.O. De

Silva, T. Bresolin, W.B.F. De

Andrade, L. Takada, F.L.B. Feitosa, F. Baldi, R. Carvalheiro, L.A.L. Chardulo, L.G. De

Albuquerque

Genome-wide association study of meat quality traits in Nellore cattle

PLoS One, 11 (2016), pp. 1-12, 10.1371/journal.pone.0157845

View Record in ScopusGoogle Scholar

S. Bolormaa, J.E. Pryce, K.E. Kemper, B.J. Hayes, Y. Zhang, B. Tier, W. Barendse, A. R everter, M.E. Goddard 
Detection of quantitative trait loci in Bos indicus and Bos taurus cattle using genome-wide association studies

Genet. Sel. Evol., 45 (2013), pp. 1-12, 10.1186/1297-9686-45-43

Google Scholar

C.U. Braz, J.F. Taylor, J.E. Decker, T. Bresolin, R. Espigolan, D.A. Garcia, D.G.M. Gord o, A.F.B. Magalhães, L.G. de Albuquerque, H.N. de Oliveira

Polymorphism analysis in genes associated with meat tenderness in Nelore cattle Meta Gene, 18 (2018), pp. 73-78, 10.1016/j.mgene.2018.08.002

ArticleDownload PDFView Record in ScopusGoogle Scholar

M. Bedhane, J. van der

Werf, C. Gondro, N. Duijvesteijn, D. Lim, B. Park, M.N. Park, R.S. Hee, S. Clark

Genome-wide association study of meat quality traits in hanwoo beef cattle using imputed whole-genome sequence data

Front. Genet., 10 (2019), pp. 1-13, 10.3389/fgene.2019.01235

Google Scholar

Z. Wang, M. Gerstein, M. Snyder

RNA-Seq: a revolutionary tool for transcriptomics

Nat. Rev. Genet., 10 (2009), pp. 57-63, 10.1038/nrg2484

CrossRefView Record in ScopusGoogle Scholar

M. Binelli, S.C. Scolari, G. Pugliesi, V. Van Hoeck, A.M. Gonella-

Diaza, S.C.S. Andrade, G.R. Gasparin, L.L. Coutinho

The transcriptome signature of the receptive bovine uterus determined at early gestation

PLoS One, 10 (2015), pp. 1-13, 10.1371/journal.pone.0122874

Google Scholar 
A. Cánovas, A. Reverter, K.L. DeAtley, R.L. Ashley, M.L. Colgrave, M.R.S. Fortes, A. I slas-Trejo, S. Lehnert, L. Porto-

Neto, G. Rincón, G.A. Silver, W.M. Snelling, J.F. Medrano, M.G. Thomas

Multi-tissue omics analyses reveal molecular regulatory networks for puberty in composite beef cattle

PLoS One, 9 (2014), pp. 1-17, 10.1371/journal.pone.0102551

Google Scholar

P.A. Alexandre, L.J.A. Kogelman, M.H.A. Santana, D. Passarelli, L.H. Pulz, P. Fantinato

Neto, P.L. Silva, P.R. Leme, R.F. Strefezzi, L.L. Coutinho, J.B.S. Ferraz, J.P. Eler, H.N.

Kadarmideen, H. Fukumasu

Liver transcriptomic networks reveal main biological processes associated with feed efficiency in beef cattle

BMC Genomics, 16 (2015), pp. 1-13, 10.1186/s12864-015-2292-8

View Record in ScopusGoogle Scholar

P.C. Tizioto, L.L. Coutinho, P.S.N. Oliveira, A.S.M. Cesar, W.J.S. Diniz, A.O. Lima, M.I

. Rocha, J.E. Decker, R.D. Schnabel, G.B. Mourão, R.R. Tullio, A. Zerlotini, J.F. Taylor, L.C.A. Regitano

Gene expression differences in Longissimus muscle of Nelore steers genetically divergent for residual feed intake

Sci. Rep., 6 (2016), p. 39493, 10.1038/srep39493

View Record in ScopusGoogle Scholar

W.J. Da Silva

Diniz, L.L. Coutinho, P.C. Tizioto, A.S.M. Cesar, C.F. Gromboni, A.R.A. Nogueira, P.S.

N. De Oliveira, M.M. De Souza, L.C. De Almeida Regitano

Iron content affects lipogenic gene expression in the muscle of Nelore beef cattle

PLoS One, 11 (2016), pp. 1-19, 10.1371/journal.pone.0161160

Google Scholar 
J. Afonso, L.L. Coutinho, P.C. Tizioto, W.J. da Silva Diniz, A.O. de

Lima, M.I.P. Rocha, C.E. Buss, B.G.N. Andrade, O. Piaya, J.V. da

Silva, L.A. Lins, C.F. Gromboni, A.R.A. Nogueira, M.R.S. Fortes, G.B. Mourao, L.C. de Almeida Regitano

Muscle transcriptome analysis reveals genes and metabolic pathways related to mineral concentration in Bos indicus

Sci. Rep., 9 (2019), pp. 1-11, 10.1038/s41598-019-49089-x

CrossRefView Record in ScopusGoogle Scholar

L.F.S. Fonseca, D.B.S. Silva, R. Barthelson, F. Baldi, J.A. Ferro, L.G. Albuquerque

Differences in global gene expression in muscle tissue of Nellore cattle with divergent meat tenderness

BMC Genomics, 18 (2017), p. 945, 10.1186/s12864-017-4323-0

View Record in ScopusGoogle Scholar

T.M. Gonçalves, L.C. De Almeida Regitano, J.E. Koltes, A.S.M. Cesar, S.C. Da Silva Andrade, G.B. Mourão, G. Gasparin, G.C.M. Moreira, E. Fritz-

Waters, J.M. Reecy, L.L. Coutinho

Gene co-expression analysis indicates potential pathways and regulators of beef tenderness in Nellore cattle

Front. Genet., 9 (2018), pp. 1-18, 10.3389/fgene.2018.00441

CrossRefGoogle Scholar

A.S.M. Cesar, L.C.A. Regitano, J.E. Koltes, E.R. Fritz-

Waters, D.P.D. Lanna, G. Gasparin, G.B. Mourão, P.S.N. Oliveira, J.M. Reecy, L.L. Cou tinho

Putative regulatory factors associated with intramuscular fat content

PLoS One, 10 (2015), pp. 1-21, 10.1371/journal.pone.0128350

CrossRefView Record in ScopusGoogle Scholar 
D.B.S. Silva, L.F.S. Fonseca, D.G. Pinheiro, M.M.M. Muniz, A.F.B. Magalhães, F. Baldi , J.A. Ferro, L.A.L. Chardulo, L.G. Albuquerque

Prediction of hub genes associated with intramuscular fat content in Nelore cattle BMC Genomics, 20 (2019), p. 520, 10.1186/s12864-019-5904-X

View Record in ScopusGoogle Scholar

J.D. Wood, M. Enser, A.V. Fisher, G.R. Nute, P.R. Sheard, R.I. Richardson, S.I. Hughes, F.M. Whittington

Fat deposition, fatty acid composition and meat quality: a review Meat Sci., 78 (2008), pp. 343-358, 10.1016/j.meatsci.2007.07.019 ArticleDownload PDFView Record in ScopusGoogle Scholar

A.S.M. Cesar, L.C.A. Regitano, M.D. Poleti, S.C.S. Andrade, P.C. Tizioto, P.S.N. Oliveir a, A.M. Felício, M.L. do Nascimento, A.S. Chaves, D.P.D. Lanna, R.R. Tullio, R.T. Nassu, J.E. Koltes, E. FritzWaters, G.B. Mourão, A. Zerlotini-Neto, J.M. Reecy, L.L. Coutinho

Differences in the skeletal muscle transcriptome profile associated with extreme values of fatty acids content

BMC Genomics, 17 (2016), pp. 1-16, 10.1186/s12864-016-3306-X

View Record in ScopusGoogle Scholar

M.P. Berton, L.F.S. Fonseca, D.F.J. Gimenez, B.L. Utembergue, A.S.M. Cesar, L.L. Cou tinho, M.V.A. de

Lemos, C. Aboujaoude, A.S.C. Pereira, R.M.O. Silva, N.B. Stafuzza, F.L.B. Feitosa, H.L .J. Chiaia, B.F. Olivieri, E. Peripolli, R.L. Tonussi, D.M. Gordo, R. Espigolan, A.M. Ferri nho, L.F. Mueller, L.G. de Albuquerque, H.N. de Oliveira, S. Duckett, F. Baldi

Gene expression profile of intramuscular muscle in Nellore cattle with extreme values of fatty acid

BMC Genomics, 17 (2016), pp. 1-16, 10.1186/s12864-016-3232-y

CrossRefGoogle Scholar 
A.S.M. Cesar, L.C.A. Regitano, J.M. Reecy, M.D. Poleti, P.S.N. Oliveira, G.B. de Oliveira, G.C.M. Moreira, M.A. Mudadu, P.C. Tizioto, J.E. Koltes, E. Fritz-

Waters, L. Kramer, D. Garrick, H. Beiki, L. Geistlinger, G.B. Mourão, A. Zerlotini, L.L. Coutinho

Identification of putative regulatory regions and transcription factors associated with intramuscular fat content traits

BMC Genomics, 19 (2018), pp. 1-20, 10.1186/s12864-018-4871-y

View Record in ScopusGoogle Scholar

W.J.S. Diniz, G. Mazzoni, L.L. Coutinho, P. Banerjee, L. Geistlinger, A.S.M. Cesar, F. B

ertolini, J. Afonso, P.S.N. De Oliveira, P.C. Tizioto, H.N. Kadarmideen, L.C.A. Regitano

Detection of co-expressed pathway modules associated with mineral concentration and meat quality in nelore cattle

Front. Genet., 10 (2019), pp. 1-12, 10.3389/fgene.2019.00210

CrossRefView Record in ScopusGoogle Scholar

B.I.G. Kappeler, L.C.A. Regitano, M.D. Poleti, A.S.M. Cesar, G.C.M. Moreira, G. Gaspa rin, L.L. Coutinho

MiRNAs differentially expressed in skeletal muscle of animals with divergent estimated breeding values for beef tenderness

BMC Mol. Biol., 20 (2019), p. 1, 10.1186/s12867-018-0118-3

View Record in ScopusGoogle Scholar

B. Silva-

Vignato, L.L. Coutinho, A.S.M. Cesar, M.D. Poleti, L.C.A. Regitano, J.C.C. Balieiro

Comparative muscle transcriptome associated with carcass traits of Nellore cattle

BMC Genomics, 18 (2017), pp. 1-13, 10.1186/s12864-017-3897-X

Google Scholar

D.B. dos Santos

Silva, L.F.S. Fonseca, A.F.B. Magalhães, M.M.M. Muniz, F. Baldi, J.A. Ferro, L.A.L. Ch ardulo, D.G. Pinheiro, L.G. Albuquerque

Transcriptome profiling of muscle in Nelore cattle phenotypically divergent for the ribeye muscle area

Genomics (2019), 10.1016/j.ygeno.2019.07.012

Google Scholar 
B. Silva-

Vignato, L.L. Coutinho, M.D. Poleti, A.S.M. Cesar, C.T. Moncau, L.C.A. Regitano, J.C.

C. Balieiro

Gene co-expression networks associated with carcass traits reveal new pathways for muscle and fat deposition in Nelore cattle 06 Biological Sciences 0604 Genetics

BMC Genomics, 20 (2019), pp. 1-13, 10.1186/s12864-018-5345-y

Google Scholar

A. D’Alessandro, L. Zolla

Meat science: from proteomics to integrated omics towards system biology

J. Proteome, 78 (2013), pp. 558-577, 10.1016/j.jprot.2012.10.023

ArticleDownload PDFView Record in ScopusGoogle Scholar

G. Paredi, M.A. Sentandreu, A. Mozzarelli, S. Fadda, K. Hollung, A.M. de Almeida

Muscle and meat: new horizons and applications for proteomics on a farm to fork perspective

J. Proteome, 88 (2013), pp. 58-82, 10.1016/j.jprot.2013.01.029

ArticleDownload PDFView Record in ScopusGoogle Scholar

B. Picard, M. Gagaoua

Meta-proteomics for the discovery of protein biomarkers of beef tenderness: an overview of integrated studies

Food Res. Int., 127 (2020), 10.1016/j.foodres.2019.108739

Google Scholar

M.D. Poleti, C.T. Moncau, B. Silva-

Vignato, A.F. Rosa, A.R. Lobo, T.R. Cataldi, J.A. Negrão, S.L. Silva, J.P. Eler, J.C. de Carvalho Balieiro

Label-free quantitative proteomic analysis reveals muscle contraction and metabolism proteins linked to ultimate $\mathbf{p H}$ in bovine skeletal muscle

Meat Sci., 145 (2018), pp. 209-219, 10.1016/j.meatsci.2018.06.041

ArticleDownload PDFView Record in ScopusGoogle Scholar

M.E. Carvalho, G. Gasparin, M.D. Poleti, A.F. Rosa, J.C.C. Balieiro, C.A. Labate, R.T. Nassu, R.R. Tullio, L.C.A. Regitano, G.B. Mourão, L.L. Coutinho

Heat shock and structural proteins associated with meat tenderness in Nellore beef cattle, a Bos indicus breed

Meat Sci., 96 (2014), pp. 1318-1324, 10.1016/j.meatsci.2013.11.014

ArticleDownload PDFView Record in ScopusGoogle Scholar 
W.A. Baldassini, C.P. Braga, L.A.L. Chardulo, J.A.I.V. Silva, J.M. Malheiros, L.G. De Albuquerque, T.T. Fernandes, P.D.M. Padilha

Bioanalytical methods for the metalloproteomics study of bovine longissimus thoracis muscle tissue with different grades of meat tenderness in the Nellore breed (Bos indicus)

Food Chem., 169 (2015), pp. 65-72, 10.1016/j.foodchem.2014.07.131

ArticleDownload PDFView Record in ScopusGoogle Scholar

A.F. Rosa, C.T. Moncau, M.D. Poleti, L.D. Fonseca, J.C.C. Balieiro, S.L.E. Silva, J.P. El er

Proteome changes of beef in Nellore cattle with different genotypes for tenderness Meat Sci., 138 (2018), pp. 1-9, 10.1016/j.meatsci.2017.12.006

ArticleDownload PDFView Record in ScopusGoogle Scholar

M.D. Poleti, L.C.A. Regitano, G.H.M.F. Souza, A.S.M. Cesar, R.C. Simas, B. SilvaVignato, G.B. Oliveira, S.C.S. Andrade, L.C. Cameron, L.L. Coutinho

Longissimus dorsi muscle label-free quantitative proteomic reveals biological mechanisms associated with intramuscular fat deposition

J. Proteome, 179 (2018), pp. 30-41, 10.1016/j.jprot.2018.02.028

ArticleDownload PDFView Record in ScopusGoogle Scholar

S. Connolly, A. Dona, L. Wilkinson-White, D. Hamblin, M. D’occhio, L.A. González

Relationship of the blood metabolome to subsequent carcass traits at slaughter in feedlot Wagyu crossbred steers

Sci. Rep., 9 (2019), p. 15139, 10.1038/s41598-019-51655-2

View Record in ScopusGoogle Scholar

A. de

Zawadzki, L.O.R. Arrivetti, M.P. Vidal, J.R. Catai, R.T. Nassu, R.R. Tullio, A. Berndt, C .R. Oliveira, A.G. Ferreira, L.F. Neves-

Junior, L.A. Colnago, L.H. Skibsted, D.R. Cardoso

Mate extract as feed additive for improvement of beef quality

Food Res. Int., 99 (2017), pp. 336-347, 10.1016/j.foodres.2017.05.033

ArticleDownload PDFView Record in ScopusGoogle Scholar

J.F.M. Gomez, D.S. Antonelo, N. Cônsolo, M. Beline, B. Pavan, C. Souza, R.S. Goulart, L. Colnago, S.L. Silva

Meat metabolomic pathway of Nellore and crossbred Angus x Nellore cattle

65th Int. Congr. Meat Sci. Technol, 65th Int. Congr. Meat Sci. Technol (2019), pp. 833836

View Record in ScopusGoogle Scholar 
D. Antonelo, N. Cônsolo, J. Gómez, M. Beline, B. Pavan, C. Souza, R. Goulart, L. Colna go

NMR-based metabolomics to assess metabolites correlated with beef sensory properties

65th Int. Congr. Meat Sci. Technol., Potsdam, Germany (2019), pp. 801-803

View Record in ScopusGoogle Scholar

U. Bernabucci, S. Biffani, L. Buggiotti, A. Vitali, N. Lacetera, A. Nardone

The effects of heat stress in Italian Holstein dairy cattle

J. Dairy Sci., 97 (2014), pp. 471-486, 10.3168/jds.2013-6611

ArticleDownload PDFCrossRefView Record in ScopusGoogle Scholar

M.R. Morgan

Climate Change 2001

(2004), 10.1256/wea.58.04

Google Scholar

N.R. St-Pierre, B. Cobanov, G. Schnitkey

Economic losses from heat stress by US livestock industries1

J. Dairy Sci., 86 (2003), pp. E52-E77, 10.3168/jds.S0022-0302(03)74040-5

ArticleDownload PDFView Record in ScopusGoogle Scholar

D.V. Armstrong

Heat stress interaction with shade and cooling

J. Dairy Sci., 77 (1994), pp. 2044-2050, 10.3168/jds.S0022-0302(94)77149-6

ArticleDownload PDFView Record in ScopusGoogle Scholar

A. Berman

An overview of heat stress relief with global warming in perspective Int. J. Biometeorol., 63 (2019), pp. 493-498, 10.1007/s00484-019-01680-7

CrossRefView Record in ScopusGoogle Scholar

H. Tian, W. Wang, N. Zheng, J. Cheng, S. Li, Y. Zhang, J. Wang

Identification of diagnostic biomarkers and metabolic pathway shifts of heatstressed lactating dairy cows

J. Proteome, 125 (2015), pp. 17-28, 10.1016/j.jprot.2015.04.014

ArticleDownload PDFView Record in ScopusGoogle Scholar

L. Min, J. Cheng, S. Zhao, H. Tian, Y. Zhang, S. Li, H. Yang, N. Zheng, J. Wang 
Plasma-based proteomics reveals immune response, complement and coagulation cascades pathway shifts in heat-stressed lactating dairy cows

J. Proteome, 146 (2016), pp. 99-108, 10.1016/j.jprot.2016.06.008

ArticleDownload PDFView Record in ScopusGoogle Scholar

L. Min, N. Zheng, S. Zhao, J. Cheng, Y. Yang, Y. Zhang, H. Yang, J. Wang

Long-term heat stress induces the inflammatory response in dairy cows revealed by plasma proteome analysis

Biochem. Biophys. Res. Commun., 471 (2016), pp. 296-302, 10.1016/j.bbrc.2016.01.185

ArticleDownload PDFView Record in ScopusGoogle Scholar

F. Ceciliani, J.J. Ceron, P.D. Eckersall, H. Sauerwein

Acute phase proteins in ruminants

J. Proteome, 75 (2012), pp. 4207-4231, 10.1016/j.jprot.2012.04.004

ArticleDownload PDFView Record in ScopusGoogle Scholar

L. Min, S. Zhao, H. Tian, X. Zhou, Y. Zhang, S. Li, H. Yang, N. Zheng, J. Wang

Metabolic responses and "omics" technologies for elucidating the effects of heat stress in dairy cows

Int. J. Biometeorol., 61 (2017), pp. 1149-1158, 10.1007/s00484-016-1283-Z

CrossRefView Record in ScopusGoogle Scholar

H. Tian, N. Zheng, W. Wang, J. Cheng, S. Li, Y. Zhang, J. Wang

Integrated metabolomics study of the milk of heat-stressed lactating dairy cows

Sci. Rep., 6 (2016), pp. 1-10, 10.1038/srep24208

CrossRefView Record in ScopusGoogle Scholar

L.A. Rispoli, J.L. Edwards, K.G. Pohler, S. Russell, R.I. Somiari, R.R. Payton, F.N. Schri ck

Heat-induced hyperthermia impacts the follicular fluid proteome of the periovulatory follicle in lactating dairy cows

PLoS One, 14 (2019), pp. 1-24, 10.1371/journal.pone.0227095

CrossRefGoogle Scholar

A.L. Skibiel, M. Zachut, B.C. do Amaral, Y. Levin, G.E. Dahl

Liver proteomic analysis of postpartum Holstein cows exposed to heat stress or cooling conditions during the dry period

J. Dairy Sci., 101 (2018), pp. 705-716, 10.3168/jds.2017-13258

ArticleDownload PDFCrossRefView Record in ScopusGoogle Scholar

L. Ma, Y. Yang, X. Zhao, F. Wang, S. Gao, D. Bu 
Heat stress induces proteomic changes in the liver and mammary tissue of dairy cows independent of feed intake: an iTRAQ study

PLoS One, 14 (2019), Article e0209182, 10.1371/journal.pone.0209182

CrossRefView Record in ScopusGoogle Scholar

M. Zachut, G. Kra, L. Livshitz, Y. Portnick, S. Yakoby, G. Friedlander, Y. Levin

Seasonal heat stress affects adipose tissue proteome toward enrichment of the Nrf2mediated oxidative stress response in late-pregnant dairy cows

J. Proteome, 158 (2017), pp. 52-61, 10.1016/j.jprot.2017.02.011

ArticleDownload PDFView Record in ScopusGoogle Scholar

K.S. Schneider, J.Y. Chan

Emerging role of $\mathrm{Nrf} 2$ in adipocytes and adipose biology

Adv. Nutr., 4 (2013), pp. 62-66, 10.3945/an.112.003103

CrossRefView Record in ScopusGoogle Scholar

A.A.K. Salama, G. Caja, S. Hamzaoui, B. Badaoui, A. Castro-

Costa, D.A.E. Façanha, M.M. Guilhermino, R. Bozzi

Different levels of response to heat stress in dairy goats

Small Rumin. Res., 121 (2014), pp. 73-79, 10.1016/j.smallrumres.2013.11.021

ArticleDownload PDFView Record in ScopusGoogle Scholar

R. Das, L. Sailo, N. Verma, P. Bharti, J. Saikia, R. Kumar Imtiwati

Impact of heat stress on health and performance of dairy animals: a review

Vet. World, 9 (2016), pp. 260-268, 10.14202/vetworld.2016.260-268

CrossRefView Record in ScopusGoogle Scholar

N. Silanikove

The physiological basis of adaptation in goats to harsh environments

Small Rumin. Res., 35 (2000), pp. 181-193, 10.1016/S0921-4488(99)00096-6

ArticleDownload PDFView Record in ScopusGoogle Scholar

S. Hamzaoui, A.A.K. Salama, E. Albanell, X. Such, G. Caja

Physiological responses and lactational performances of late-lactation dairy goats under heat stress conditions

J. Dairy Sci., 96 (2013), pp. 6355-6365, 10.3168/jds.2013-6665

ArticleDownload PDFCrossRefView Record in ScopusGoogle Scholar

A. Contreras-Jodar, A.A.K. Salama, S. Hamzaoui, M. Vailati-Riboni, G. Caja, J.J. Loor 
Effects of chronic heat stress on lactational performance and the transcriptomic profile of blood cells in lactating dairy goats

J. Dairy Res., 85 (2018), pp. 423-430, 10.1017/S0022029918000705

CrossRefView Record in ScopusGoogle Scholar

A. Sevi, M. Caroprese

Impact of heat stress on milk production, immunity and udder health in sheep: a critical review

Small Rumin. Res., 107 (2012), pp. 1-7, 10.1016/j.smallrumres.2012.07.012

ArticleDownload PDFView Record in ScopusGoogle Scholar

A. Salama, G. Caja, S. Hamzaoui, X. Such, E. Albanell, B. Badaoui, J. Loor

Thermal stress in ruminants: responses and strategies for alleviation

J. Villalba, X. Manteca (Eds.), Anim. Welf. Extensive Prod. Syst, 5M

publishing, Sheffield, UK (2016), pp. 11-36

View Record in ScopusGoogle Scholar

A.A.K. Salama, M. Duque, L. Wang, K. Shahzad, M. Olivera, J.J. Loor

Enhanced supply of methionine or arginine alters mechanistic target of rapamycin signaling proteins, messenger RNA, and microRNA abundance in heat-stressed bovine mammary epithelial cells in vitro

J. Dairy Sci., 102 (2019), pp. 2469-2480, 10.3168/jds.2018-15219

ArticleDownload PDFCrossRefView Record in ScopusGoogle Scholar

F. Koch, U. Thom, E. Albrecht, R. Weikard, W. Nolte, B. Kuhla, C. Kuehn

Heat stress directly impairs gut integrity and recruits distinct immune cell populations into the bovine intestine

Proc. Natl. Acad. Sci. U. S. A., 116 (2019), pp. 10333-10338, 10.1073/pnas.1820130116

CrossRefView Record in ScopusGoogle Scholar

A. Contreras-Jodar, N.H. Nayan, S. Hamzaoui, G. Caja, A.A.K. Salama

Heat stress modifies the lactational performances and the urinary metabolomic profile related to gastrointestinal microbiota of dairy goats

PLoS One, 14 (2019), pp. 1-14, 10.1371/journal.pone.0202457

Google Scholar

I.M.T. Thompson, S. Tao, A.P.A. Monteiro, K.C. Jeong, G.E. Dahl

Effect of cooling during the dry period on immune response after Streptococcus uberis intramammary infection challenge of dairy cows

J. Dairy Sci., 97 (2014), pp. 7426-7436, 10.3168/jds.2013-7621

ArticleDownload PDFCrossRefView Record in ScopusGoogle Scholar 
A.A.K. Salama, A. Contreras-Jodar, S. Love, N. Mehaba, X. Such, G. Caja

Milk yield, milk composition, and milk metabolomics of dairy goats intramammarychallenged with lipopolysaccharide under heat stress conditions

Sci. Rep., 10 (2020), 10.1038/s41598-020-61900-8

Google Scholar

S.K. Wall, L.E. Hernández-Castellano, A. Ahmadpour, R.M. Bruckmaier, O. Wellnitz

Differential glucocorticoid-induced closure of the blood-milk barrier during lipopolysaccharide- and lipoteichoic acid-induced mastitis in dairy cows

J. Dairy Sci., 99 (2016), pp. 7544-7553, 10.3168/jds.2016-11093

ArticleDownload PDFCrossRefView Record in ScopusGoogle Scholar

[93]

S.K. Wall, O. Wellnitz, L.E. Hernández-Castellano, A. Ahmadpour, R.M. Bruckmaier

Supraphysiological oxytocin increases the transfer of immunoglobulins and other blood components to milk during lipopolysaccharide- and lipoteichoic acid-induced mastitis in dairy cows

J. Dairy Sci., 99 (2016), pp. 9165-9173, 10.3168/jds.2016-11548

ArticleDownload PDFCrossRefView Record in ScopusGoogle Scholar $\lceil 94\rceil$

A. Almeida, L. Schwalbach, H. de Waal, J.P.C. Greyling, L. Cardoso

A study of mineral status in the carcass of boer goat bucks: influence of suplementation

Arch. Zootec., 55 (2006), pp. 313-316

View Record in ScopusGoogle Scholar

[95]

J.R. Lérias, L.E. Hernández-Castellano, A. Morales-

delaNuez, S.S. Araújo, N. Castro, A. Argüello, J. Capote, A.M. Almeida

Body live weight and milk production parameters in the Majorera and Palmera goat breeds from the Canary Islands: influence of weight loss

Trop. Anim. Health Prod., 45 (2013), pp. 1731-1736, 10.1007/s11250-013-0423-2

CrossRefView Record in ScopusGoogle Scholar

[96]

A.M. Almeida

The Damara in the context of Southern Africa fat-tailed sheep breeds

Trop. Anim. Health Prod., 43 (2011), pp. 1427-1441, 10.1007/s11250-011-9868-3

CrossRefView Record in ScopusGoogle Scholar

[97]

A.M. Almeida, T. Kilminster, T. Scanlon, S.S. Araújo, J. Milton, C. Oldham, J.C. Greeff 
Assessing carcass and meat characteristics of Damara, Dorper and Australian Merino lambs under restricted feeding

Trop. Anim. Health Prod., 45 (2013), pp. 1305-1311, 10.1007/s11250-013-0361-Z

CrossRefView Record in ScopusGoogle Scholar

\section{[98]}

T.T. Scanlon, A.M. Almeida, A. van

Burgel, T. Kilminster, J. Milton, J.C. Greeff, C. Oldham

Live weight parameters and feed intake in Dorper, Damara and Australian Merino lambs exposed to restricted feeding

Small Rumin. Res., 109 (2013), pp. 101-106, 10.1016/j.smallrumres.2012.08.004

ArticleDownload PDFView Record in ScopusGoogle Scholar

$$
\text { [99] }
$$

S.P. Alves, R.J.B. Bessa, M.A.G. Quaresma, T. Kilminster, T. Scanlon, C. Oldham, J. Mi lton, J. Greeff, A.M. Almeida

Does the fat tailed damara ovine breed have a distinct lipid metabolism leading to a high concentration of branched chain fatty acids in tissues?

PLoS One, 8 (2013), pp. 1-9, 10.1371/journal.pone.0077313

CrossRefGoogle Scholar

$$
\text { [100] }
$$

S. van Harten, T. Kilminster, T. Scanlon, J. Milton, C. Oldham, J. Greeff, A.M. Almeida

Fatty acid composition of the ovine longissimus dorsi muscle: effect of feed restriction in three breeds of different origin

J. Sci. Food Agric., 96 (2016), pp. 1777-1782, 10.1002/jsfa.7285

CrossRefView Record in ScopusGoogle Scholar

\section{[101]}

A.M. Almeida, R.G. Palhinhas, T. Kilminster, T. Scanlon, S. van

Harten, J. Milton, D. Blache, J. Greeff, C. Oldham, A.V. Coelho, L.A. Cardoso

The effect of weight loss on the muscle proteome in the damara, dorper and australian merino ovine breeds

PLoS One, 11 (2016), Article e0146367, 10.1371/journal.pone.0146367

CrossRefView Record in ScopusGoogle Scholar

A.M. Ferreira, J. Grossmann, C. Fortes, T. Kilminster, T. Scanlon, J. Milton, J. Greeff, C. Oldham, P. Nanni, A.M. Almeida

The sheep (Ovis aries) muscle proteome: decoding the mechanisms of tolerance to Seasonal Weight Loss using label-free proteomics

J. Proteome, 161 (2017), pp. 57-67, 10.1016/j.jprot.2017.03.020

ArticleDownload PDFView Record in ScopusGoogle Scholar

$[103]$

B.A. Miller, A. Chapwanya, T. Kilminster, T. Scanlon, J. Milton, H. Osório, C. Oldham, J. Greeff, D.R. Bergfelt, A.M.O. Campos, A.M. Almeida 
The ovine hepatic mitochondrial proteome: understanding seasonal weight loss tolerance in two distinct breeds

PLoS One, 14 (2019), Article e0212580, 10.1371/journal.pone.0212580

CrossRefView Record in ScopusGoogle Scholar

B. Miller, N. Selevsek, J. Grossmann, T. Kilminster, T. Scanlon, M. Daniels, P. Nanni, J. Milton, C. Oldham, J. Greeff, A. Chapwanya, D. Bergfelt, A.M. de Almeida

Ovine liver proteome: assessing mechanisms of seasonal weight loss tolerance between Merino and Damara sheep

J. Proteome, 191 (2019), pp. 180-190, 10.1016/i.jprot.2018.02.018

ArticleDownload PDFView Record in ScopusGoogle Scholar

M. Palma, T. Scanlon, T. Kilminster, J. Milton, C. Oldham, J. Greeff, M. Matzapetakis, A.M. Almeida

The hepatic and skeletal muscle ovine metabolomes as affected by weight loss: a study in three sheep breeds using NMR-metabolomics

Sci. Rep., 6 (2016), pp. 1-11, 10.1038/srep39120

View Record in ScopusGoogle Scholar

D.M. Ribeiro, M.S. Madeira, T. Kilminster, T. Scanlon, C. Oldham, J. Greeff, J.P.B. Frei re, M.P. Mourato, J.A.M. Prates, A.M. Almeida

Amino acid profiles of muscle and liver tissues of Australian Merino, Damara and Dorper lambs under restricted feeding

J. Anim. Physiol. Anim. Nutr. (Berl) (2019), 10.1111/jpn.13148

Google Scholar

J.R. Lérias, R. Peña, L.E. Hernández-

Castellano, J. Capote, N. Castro, A. Argüello, S.S. Araújo, Y. Saco, A. Bassols, A.M. Al meida

Establishment of the biochemical and endocrine blood profiles in the Majorera and Palmera dairy goat breeds: the effect of feed restriction 
M. Palma, L.E. Hernández-

Castellano, N. Castro, A. Arguëllo, J. Capote, M. Matzapetakis, A.M. De Almeida

NMR-metabolomics profiling of mammary gland secretory tissue and milk serum in two goat breeds with different levels of tolerance to seasonal weight loss Mol. BioSyst., 12 (2016), pp. 2094-2107, 10.1039/c5mb00851d

View Record in ScopusGoogle Scholar

L.E. Hernández-

Castellano, A.M. Ferreira, P. Nanni, J. Grossmann, A. Argüello, J. Capote, G. Cai, J. Lip

polis, N. Castro, A.M. de Almeida

The goat (Capra hircus) mammary gland secretory tissue proteome as influenced by weight loss: a study using label free proteomics

J. Proteome, 145 (2016), pp. 60-69, 10.1016/j.jprot.2016.03.030

ArticleDownload PDFView Record in ScopusGoogle Scholar

G. Cugno, J.R. Parreira, E. Ferlizza, L.E. Hernández-

Castellano, M. Carneiro, J. Renaut, N. Castro, A. Arguello, J. Capote, A.M.O. Campos, A .M. Almeida

The Goat (Capra hircus) mammary gland mitochondrial proteome: a study on the effect of weight loss using blue-native page and two-dimensional gel electrophoresis PLoS One, 11 (2016), pp. 1-18, 10.1371/journal.pone.0151599

Google Scholar

L. Hernández-Castellano, A. Almeida, N. Castro, A. Arguello 
The colostrum proteome, ruminant nutrition and immunity: a review Curr. Protein Pept. Sci., 15 (2014), pp. 64-74, 10.2174/1389203715666140221124622 CrossRefView Record in ScopusGoogle Scholar

C.C.L. Chase, D.J. Hurley, A.J. Reber

Neonatal immune development in the calf and its impact on vaccine response Vet. Clin. North Am. Food Anim. Pract., 24 (2008), pp. 87-

104, 10.1016/j.cvfa.2007.11.001

ArticleDownload PDFView Record in ScopusGoogle Scholar

A. Scoot, B.D. Owen, J.L. Agar

Influence of orally administered porcine immunoglobulins on survival and performance of newborn colostrum-deprived pigs

J. Anim. Sci., 35 (1972), pp. 1201-1205, 10.2527/jas1972.3561201x

CrossRefView Record in ScopusGoogle Scholar

J.W. Tyler, D.D. Hancock, J.G. Thorne, C.C. Gay, J.M. Gay

Partitioning the mortality risk associated with inadequate passive transfer of colostral immunoglobulins in dairy calves

J. Vet. Intern. Med., 13 (1999), pp. 335-337, 10.1111/j.1939-1676.1999.tb02191.x

View Record in ScopusGoogle Scholar

A. Argüello, N. Castro, M.J. Zamorano, A. Castroalonso, J. Capote

Passive transfer of immunity in kid goats fed refrigerated and frozen goat colostrum and commercial sheep colostrum

Small Rumin. Res., 54 (2004), pp. 237-241, 10.1016/j.smallrumres.2003.11.008

ArticleDownload PDFView Record in ScopusGoogle Scholar 
L.E. Hernández-Castellano, A. Argüello, A.M. Almeida, N. Castro, E. Bendixen

Colostrum protein uptake in neonatal lambs examined by descriptive and quantitative liquid chromatography-tandem mass spectrometry

J. Dairy Sci., 98 (2015), pp. 135-147, 10.3168/jds.2014-8143

ArticleDownload PDFCrossRefView Record in ScopusGoogle Scholar

L.E. Hernández-

Castellano, A.M. Almeida, M. Ventosa, A.V. Coelho, N. Castro, A. Argüello

The effect of colostrum intake on blood plasma proteome profile in newborn lambs: low abundance proteins

BMC Vet. Res., 10 (2014), pp. 1-9, 10.1186/1746-6148-10-85

Google Scholar

L.E. Hernández-Castellano, A. Morales-delaNuez, D. Sánchez-Macías, I. MorenoIndias, A. Torres, J. Capote, A. Argüello, N. Castro

The effect of colostrum source (goat vs. sheep) and timing of the first colostrum feeding ( $2 \mathrm{~h}$ vs. 14h after birth) on body weight and immune status of artificially reared newborn lambs

J. Dairy Sci., 98 (2015), pp. 204-210, 10.3168/jds.2014-8350

ArticleDownload PDFCrossRefView Record in ScopusGoogle Scholar

L.E. Hernández-Castellano, A.M. Almeida, J. Renaut, A. Argüello, N. Castro

A proteomics study of colostrum and milk from the two major small ruminant dairy breeds from the Canary Islands: a bovine milk comparison perspective J. Dairy Res., 83 (2016), pp. 366-374, 10.1017/S0022029916000273

View Record in ScopusGoogle Scholar 
A. Nissen, P.H. Andersen, E. Bendixen, K.L. Ingvartsen, C.M. Røntved

Colostrum and milk protein rankings and ratios of importance to neonatal calf health using a proteomics approach

J. Dairy Sci., 100 (2017), pp. 2711-2728, 10.3168/jds.2016-11722

ArticleDownload PDFCrossRefView Record in ScopusGoogle Scholar

M. Samuel, D. Chisanga, M. Liem, S. Keerthikumar, S. Anand, C.S. Ang, C.G. Adda, E. Versteegen, M. Jois, S. Mathivanan

Bovine milk-derived exosomes from colostrum are enriched with proteins implicated in immune response and growth

Sci. Rep., 7 (2017), pp. 1-10, 10.1038/s41598-017-06288-8

CrossRefView Record in ScopusGoogle Scholar

W.Z. Wu, X.Q. Wang, G.Y. Wu, S.W. Kim, F. Chen, J.J. Wang

Differential composition of proteomes in sow colostrum and milk from anterior and posterior mammary glands

J. Anim. Sci., 88 (2010), pp. 2657-2664, 10.2527/jas.2010-2972

CrossRefView Record in ScopusGoogle Scholar

S. Ogawa, T. Tsukahara, R. Nishibayashi, M. Nakatani, M. Okutani, N. Nakanishi, K. Us hida, R. Inoue

Shotgun proteomic analysis of porcine colostrum and mature milk

Anim. Sci. J., 85 (2014), pp. 440-448, 10.1111/asj.12165

CrossRefView Record in ScopusGoogle Scholar 
M.V. Curtasu, P.K. Theil, M.S. Hedemann

Metabolomic profiles of colostrum and milk from lactating sows

J. Anim. Sci., 94 (2016), pp. 272-275, 10.2527/jas2015-9769

CrossRefView Record in ScopusGoogle Scholar

Y. Qi, X. Zhao, D. Huang, X. Pan, Y. Yang, H. Zhao, H. Hu, G. Cheng

Exploration of the relationship between intestinal colostrum or milk, and serum metabolites in neonatal calves by metabolomics analysis

J. Agric. Food Chem., 66 (2018), pp. 7200-7208, 10.1021/acs.jafc.8b01621

CrossRefView Record in ScopusGoogle Scholar

X.W. Zhao, Y.X. Qi, D.W. Huang, X.C. Pan, G.L. Cheng, H.L. Zhao, Y.X. Yang

Changes in serum metabolites in response to ingested colostrum and milk in neonatal calves, measured by nuclear magnetic resonance-based metabolomics analysis

J. Dairy Sci., 101 (2018), pp. 7168-7181, 10.3168/jds.2017-14287

ArticleDownload PDFCrossRefView Record in ScopusGoogle Scholar

S.T. Morrin, J.A. Lane, M. Marotta, L. Bode, S.D. Carrington, J.A. Irwin, R.M. Hickey

Bovine colostrum-driven modulation of intestinal epithelial cells for increased commensal colonisation

Appl. Microbiol. Biotechnol., 103 (2019), pp. 2745-2758, 10.1007/s00253-019-09642-0

CrossRefView Record in ScopusGoogle Scholar 
D.P. Morgavi, W.J. Kelly, P.H. Janssen, G.T. Attwood

Rumen microbial (meta)genomics and its application to ruminant production

Animal., 7 (2013), pp. 184-201, 10.1017/S1751731112000419

ArticleDownload PDFView Record in ScopusGoogle Scholar

G. Henderson, F. Cox, S. Ganesh, A. Jonker, W. Young, P.H. Janssen, L. Abecia, E. Ang arita, P. Aravena, G.N. Arenas, C. Ariza, G.T. Attwood, J.M. Avila, J. Avila-

Stagno, A. Bannink, R. Barahona, M. Batistotti, M.F. Bertelsen, A. Brown-

Kav, A.M. Carvajal, L. Cersosimo, A.V. Chaves, J. Church, N. Clipson, M.A. Cobos-

Peralta, A.L. Cookson, S. Cravero, O.C. Carballo, K. Crosley, G. Cruz, M.C. Cucchi, R.

De La Barra, A.B. De Menezes, E. Detmann, K. Dieho, J. Dijkstra, W.L.S.

Dos Reis, M.E.R. Dugan, S.H. Ebrahimi, E. Eythórsdóttir, F.N. Fon, M. Fraga, F. Franco, C. Friedeman, N. Fukuma, D. Gagić, I. Gangnat, D.J. Grilli, L.L. Guan, V.H. Miri, E. He rnandez-

Sanabria, A.X.I. Gomez, O.A. Isah, S. Ishaq, E. Jami, J. Jelincic, J. Kantanen, W.J. Kelly, S.H. Kim, A. Klieve, Y. Kobayashi, S. Koike, J. Kopecny, T.N. Kristensen, S.J. Krizsan, H. LaChance, M. Lachman, W.R. Lamberson, S. Lambie, J. Lassen, S.C. Leahy, S.S. Le e, F. Leiber, E. Lewis, B. Lin, R. Lira, P. Lund, E. Macipe, L.L. Mamuad, H.C. Mantova ni, G.A. Marcoppido, C. Márquez, C. Martin, G. Martinez, M.E. Martinez, O.L. Mayorga , T.A. McAllister, C. McSweeney, L. Mestre, E. Minnee, M. Mitsumori, I. Mizrahi, I. Mo lina, A. Muenger, C. Munoz, B. Murovec, J. Newbold, V. Nsereko, M. O'Donovan, S. O

kunade, B. O’Neill, S. Ospina, D. Ouwerkerk, D. Parra, L.G.R. Pereira, C. Pinares-

Patino, P.B. Pope, M. Poulsen, M. Rodehutscord, T. Rodriguez, K. Saito, F. Sales, C. Sau er, K. Shingfield, N. Shoji, J. Simunek, Z. Stojanović-

Radić, B. Stres, X. Sun, J. Swartz, Z.L. Tan, I. Tapio, T.M. Taxis, N. Tomkins, E. Ungerf eld, R. Valizadeh, P. Van Adrichem, J. Van Hamme, W. Van

Hoven, G. Waghorn, R.J. Wallace, M. Wang, S.M. Waters, K. Keogh, M. Witzig, A.D.G. Wright, H. Yamano, T. Yan, D.R. Yanez-

Ruiz, C.J. Yeoman, R. Zambrano, J. Zeitz, M. Zhou, H.W. Zhou, C.X. Zou, P. Zunino

Rumen microbial community composition varies with diet and host, but a core microbiome is found across a wide geographical range

Sci. Rep., 5 (2015), 10.1038/srep14567.

Google Scholar

R.J. Gruninger, G.O. Ribeiro, A. Cameron, T.A. McAllister 
Invited review: application of meta-omics to understand the dynamic nature of the rumen microbiome and how it responds to diet in ruminants

Animal., 13 (2019), pp. 1843-1854, 10.1017/S1751731119000752

ArticleDownload PDFCrossRefView Record in ScopusGoogle Scholar

A. Santra, S.A. Karim

Rumen manipulation to improve animal productivity

Asian-Australasian J. Anim. Sci., 16 (2003), pp. 748-763, 10.5713/ajas.2003.748

CrossRefView Record in ScopusGoogle Scholar

K.M. Singh, S.J. Jakhesara, P.G. Koringa, D.N. Rank, C.G. Joshi

Metagenomic analysis of virulence-associated and antibiotic resistance genes of microbes in rumen of Indian buffalo (Bubalus bubalis)

Gene., 507 (2012), pp. 146-151, 10.1016/j.gene.2012.07.037

ArticleDownload PDFView Record in ScopusGoogle Scholar

F. Li, A.L.A. Neves, B. Ghoshal, L.L. Guan

Symposium review: mining metagenomic and metatranscriptomic data for clues about microbial metabolic functions in ruminants 1

J. Dairy Sci., 101 (2018), pp. 5605-5618, 10.3168/jds.2017-13356

ArticleDownload PDFCrossRefView Record in ScopusGoogle Scholar

M. Wanapat

Rumen manipulation to increase the efficient use of local feed resources and productivity of ruminants in the tropics

Asian-Australasian J. Anim. Sci., 13 (2000), pp. 59-67

View Record in ScopusGoogle Scholar 
E.R. Duarte, F.O. Abrão, I.C.O. Ribeiro, E.A. Vieira, A.C. Nigri, K.L. Silva, G.F.V. Júni or, S.M.P. Barreto, L.C. Geraseev

Rumen protozoa of different ages of beef cattle raised in tropical pastures during the dry season

J. Appl. Anim. Res., 46 (2018), pp. 1457-1461, 10.1080/09712119.2018.1530676

CrossRefView Record in ScopusGoogle Scholar

S. Deusch, B. Tilocca, A. Camarinha-Silva, J. Seifert

News in livestock research - use of Omics-technologies to study the microbiota in the gastrointestinal tract of farm animals

Comput. Struct. Biotechnol. J., 13 (2015), pp. 55-63, 10.1016/i.csbj.2014.12.005

ArticleDownload PDFView Record in ScopusGoogle Scholar

S.E. Denman, D.P. Morgavi, C.S. Mcsweeney

Review: the application of omics to rumen microbiota function

Animal., 12 (2018), pp. S233-S245, 10.1017/S175173111800229X

View Record in ScopusGoogle Scholar

J.R.P. Arjona, C.A. Sandoval-Castro

Rumen metagenome sequencing technology

Trop. Subtrop. Agroecosyst., 21 (2018), pp. 587-598

Google Scholar

E. Jami, I. Mizrahi

Composition and similarity of bovine rumen microbiota across individual animals PLoS One, 7 (2012), pp. 1-8, 10.1371/journal.pone.0033306

CrossRefView Record in ScopusGoogle Scholar

N.M. Nathani, A.K. Patel, P.S. Dhamannapatil, R.K. Kothari, K.M. Singh, C.G. Joshi 
Comparative evaluation of rumen metagenome community using qPCR and MGRAST

AMB Express, 3 (2013), pp. 1-8, 10.1186/2191-0855-3-1

View Record in ScopusGoogle Scholar

V. Patel, A.K. Patel, N.R. Parmar, A.B. Patel, B. Reddy, C.G. Joshi

Characterization of the rumen microbiome of Indian Kankrej cattle (Bos indicus) adapted to different forage diet

Appl. Microbiol. Biotechnol., 98 (2014), pp. 9749-9761, 10.1007/s00253-014-6153-1

CrossRefView Record in ScopusGoogle Scholar

S.E. Denman, G.M. Fernandez, T. Shinkai, M. Mitsumori, C.S. McSweeney

Metagenomic analysis of the rumen microbial community following inhibition of methane formation by a halogenated methane analog

Front. Microbiol., 6 (2015), pp. 1-12, 10.3389/fmicb.2015.01087

View Record in ScopusGoogle Scholar

L.T. Kishi, R.B. de Jesus, C.D. Pavani, E.G.M. Lemos, J.A.M. de Souza

Metagenomic assembly and draft genome sequence of an uncharacterized Prevotella sp. from Nelore rumen

Genome Announc., 3 (2015), pp. 6-7, 10.1128/genomeA.00723-15

Google Scholar

R.Y. Zhang, Y.J. Liu, Y.Y. Yin, W. Jin, S.Y. Mao, J.H. Liu

Response of rumen microbiota, and metabolic profiles of rumen fluid, liver and serum of goats to high-grain diets

Animal., 13 (2019), pp. 1855-1864, 10.1017/S1751731118003671

ArticleDownload PDFCrossRefView Record in ScopusGoogle Scholar

L.D. Lopes, A.O. de Souza Lima, R.G. Taketani, P. Darias, L.R.F. da

Silva, E.M. Romagnoli, H. Louvandini, A.L. Abdalla, R. Mendes

Exploring the sheep rumen microbiome for carbohydrate-active enzymes, Antonie van Leeuwenhoek

Int. J. Gen. Mol. Microbiol., 108 (2015), pp. 15-30, 10.1007/s10482-015-0459-6

CrossRefView Record in ScopusGoogle Scholar

K.M. Singh, B. Reddy, D. Patel, A.K. Patel, N. Parmar, A. Patel, J.B. Patel, C.G. Joshi

High potential source for biomass degradation enzyme discovery and environmental aspects revealed through metagenomics of Indian buffalo rumen

Biomed. Res. Int., 2014 (2014), 10.1155/2014/267189

Google Scholar 
V.S. Prajapati, H.J. Purohit, D.V. Raje, N. Parmar, A.B. Patel, O.A.H. Jones, C.G. Joshi

The effect of a high-roughage diet on the metabolism of aromatic compounds by rumen microbes: a metagenomic study using Mehsani buffalo (Bubalus bubalis) Appl. Microbiol. Biotechnol., 100 (2016), pp. 1319-1331, 10.1007/s00253-015-7239-0 CrossRefView Record in ScopusGoogle Scholar

S. Al-Masaudi, A. El Kaoutari, E. Drula, H. Al-

Mehdar, E.M. Redwan, V. Lombard, B. Henrissat

A metagenomics investigation of carbohydrate-active enzymes along the gastrointestinal tract of Saudi sheep

Front. Microbiol., 8 (2017), 10.3389/fmicb.2017.00666

Google Scholar

K.J. Rashamuse, D.F. Visser, F. Hennessy, J. Kemp, M.P. Roux-Van Der

Merwe, J. Badenhorst, T. Ronneburg, R. Francis-Pope, D. Brady

Characterisation of two bifunctional cellulase-Xylanase enzymes isolated from a bovine rumen metagenome library

Curr. Microbiol., 66 (2013), pp. 145-151, 10.1007/s00284-012-0251-Z

CrossRefView Record in ScopusGoogle Scholar

V.L. Jose, T. Appoothy, R.P. More, A.S. Arun

Metagenomic insights into the rumen microbial fibrolytic enzymes in Indian crossbred cattle fed finger millet straw

AMB Express, 7 (2017), 10.1186/s13568-016-0310-0

Google Scholar

E.M. Ross, S. Petrovski, P.J. Moate, B.J. Hayes

Metagenomics of rumen bacteriophage from thirteen lactating dairy cattle BMC Microbiol., 13 (2013), 10.1186/1471-2180-13-242

Google Scholar

S. Namonyo, M. Wagacha, S. Maina, L. Wambua, M. Agaba

Correction to: a metagenomic study of the rumen virome in domestic caprids (Archives of Virology, (2018), 163, 12, (3415-3419), 10.1007/s00705-018-4022-4)

Arch. Virol., 163 (2018), p. 3421, 10.1007/s00705-018-4046-9

CrossRefView Record in ScopusGoogle Scholar

D.P. Poppi, S.P. Quigley, T.A.C.C. da Silva, S.R. McLennan

Challenges of beef cattle production from tropical pastures 
Rev. Bras. Zootec., 47 (2018), 10.1590/rbz4720160419

Google Scholar

L. Bensoussan, S. Moraï, B. Dassa, N. Friedman, B. Henrissat, V. Lombard, E.A. Bayer, I. Mizrahi

Broad phylogeny and functionality of cellulosomal components in the bovine rumen microbiome

Environ. Microbiol., 19 (2017), pp. 185-197, 10.1111/1462-2920.13561

CrossRefView Record in ScopusGoogle Scholar

B. Dassa, I. Borovok, V. Ruimy-

Israeli, R. Lamed, H.J. Flint, S.H. Duncan, B. Henrissat, P. Coutinho, M. Morrison, P. M osoni, C.J. Yeoman, B.A. White, E.A. Bayer

Rumen cellulosomics: divergent fiber-degrading strategies revealed by comparative genome-wide analysis of six ruminococcal strains

PLoS One, 9 (2014), 10.1371/journal.pone.0099221

Google Scholar

R.A. Batista-García, M. del Rayo Sánchez-

Carbente, P. Talia, S.A. Jackson, N.D. O’Leary, A.D.W. Dobson, J.L. Folch-Mallol

From lignocellulosic metagenomes to lignocellulolytic genes: trends, challenges and future prospects, Biofuels

Bioprod. Biorefining., 10 (2016), pp. 864-882, 10.1002/bbb.1709

CrossRefView Record in ScopusGoogle Scholar

E. Jami, A. Israel, A. Kotser, I. Mizrahi

Exploring the bovine rumen bacterial community from birth to adulthood

ISME J., 7 (2013), pp. 1069-1079, 10.1038/ismej.2013.2

CrossRefView Record in ScopusGoogle Scholar

R.B. de Jesus, Y.T. Granja-Salcedo, J.D. Messana, L.T. Kishi, E.G.M. Lemos, J.A.M. de Souza, T.T. Berchielli

Characterization of ruminal bacteria in grazing nellore steers

Rev. Colomb. Ciencias Pecu., 32 (2019), pp. 248-260, 10.17533/udea.rccp.v32n4a01

View Record in ScopusGoogle Scholar

A.V. Klieve, D. Hennessy, D. Ouwerkerk, R.J. Forster, R.I. Mackie, G.T. Attwood

Establishing populations of Megasphaera elsdenii YE 34 and Butyrivibrio fibrisolvens YE 44 in the rumen of cattle fed high grain diets

J. Appl. Microbiol., 95 (2003), pp. 621-630, 10.1046/j.1365-2672.2003.02024.x

View Record in ScopusGoogle Scholar 
R.J. Pandit, A.T. Hinsu, S.H. Patel, S.J. Jakhesara, P.G. Koringa, F. Bruno, A. Psifidi, S. V. Shah, C.G. Joshi

Microbiota composition, gene pool and its expression in Gir cattle (Bos indicus) rumen under different forage diets using metagenomic and metatranscriptomic approaches

Syst. Appl. Microbiol., 41 (2018), pp. 374-385, 10.1016/j.syapm.2018.02.002

ArticleDownload PDFView Record in ScopusGoogle Scholar

R. Zhang, W. Zhu, L. Jiang, S. Mao

Comparative metabolome analysis of ruminal changes in Holstein dairy cows fed low- or high-concentrate diets

Metabolomics., 13 (2017), pp. 1-15, 10.1007/s11306-017-1204-0

CrossRefView Record in ScopusGoogle Scholar

S. Kumar, P.K. Choudhury, M.D. Carro, G.W. Griffith, S.S. Dagar, M. Puniya, S. Calabr o, S.R. Ravella, T. Dhewa, R.C. Upadhyay, S.K. Sirohi, S.S. Kundu, M. Wanapat, A.K. P uniya

New aspects and strategies for methane mitigation from ruminants

Appl. Microbiol. Biotechnol., 98 (2014), pp. 31-44, 10.1007/s00253-013-5365-0

View Record in ScopusGoogle Scholar

C.S. Cunha, C.M. Veloso, M.I. Marcondes, H.C. Mantovani, T.R. Tomich, L.G.R. Pereir a, M.F.L. Ferreira, K.A. Dill-McFarland, G. Suen

Assessing the impact of rumen microbial communities on methane emissions and production traits in Holstein cows in a tropical climate Syst. Appl. Microbiol., 40 (2017), pp. 492-499, 10.1016/j.syapm.2017.07.008

ArticleDownload PDFView Record in ScopusGoogle Scholar

I.S. Cunha, C.C. Barreto, O.Y.A. Costa, M.A. Bomfim, A.P. Castro, R.H. Kruger, B.F. Q uirino

Bacteria and Archaea community structure in the rumen microbiome of goats (Capra hircus) from the semiarid region of Brazil

Anaerobe., 17 (2011), pp. 118-124, 10.1016/j.anaerobe.2011.04.018

ArticleDownload PDFView Record in ScopusGoogle Scholar

Z. Zhang, D. Xu, L. Wang, J. Hao, J. Wang, X. Zhou, W. Wang, Q. Qiu, X. Huang, J. Zh ou, R. Long, F. Zhao, P. Shi

Convergent Evolution of Rumen Microbiomes in High-Altitude Mammals

Curr. Biol., 26 (2016), pp. 1873-1879, 10.1016/j.cub.2016.05.012

ArticleDownload PDFCrossRefView Record in ScopusGoogle Scholar 
S.A. Huws, C.J. Creevey, L.B. Oyama, I. Mizrahi, S.E. Denman, M. Popova, R. MuñozTamayo, E. Forano, S.M. Waters, M. Hess, I. Tapio, H. Smidt, S.J. Krizsan, D.R. YáñezRuiz, A. Belanche, L. Guan, R.J. Gruninger, T.A. McAllister, C.J. Newbold, R. Roehe, R .J. Dewhurst, T.J. Snelling, M. Watson, G. Suen, E.H. Hart, A.H. Kingston-

Smith, N.D. Scollan, R.M. Do

Prado, E.J. Pilau, H.C. Mantovani, G.T. Attwood, J.E. Edwards, N.R. McEwan, S. Morris son, O.L. Mayorga, C. Elliott, D.P. Morgavi

Addressing global ruminant agricultural challenges through understanding the rumen microbiome: past, present, and future

Front. Microbiol., 9 (2018), pp. 1-33, 10.3389/fmicb.2018.02161

CrossRefGoogle Scholar

B. Mesuere, F. Van der

Jeugt, T. Willems, T. Naessens, B. Devreese, L. Martens, P. Dawyndt

High-throughput metaproteomics data analysis with Unipept: a tutorial

J. Proteome, 171 (2018), pp. 11-22, 10.1016/j.jprot.2017.05.022

ArticleDownload PDFView Record in ScopusGoogle Scholar

T.J. Snelling, R.J. Wallace

The rumen microbial metaproteome as revealed by SDS-PAGE BMC Microbiol., 17 (2017), pp. 1-10, 10.1186/s12866-016-0917-y

CrossRefView Record in ScopusGoogle Scholar

S. Deusch, J. Seifert

Catching the tip of the iceberg - evaluation of sample preparation protocols for metaproteomic studies of the rumen microbiota

Proteomics., 15 (2015), pp. 3590-3595, 10.1002/pmic.201400556

CrossRefView Record in ScopusGoogle Scholar

F. Saleem, S. Bouatra, A.C. Guo, N. Psychogios, R. Mandal, S.M. Dunn, B.N. Ametaj, D .S. Wishart

The bovine ruminal fluid metabolome

Metabolomics., 9 (2013), pp. 360-378, 10.1007/s11306-012-0458-9

CrossRefView Record in ScopusGoogle Scholar

F. Saleem, B.N. Ametaj, S. Bouatra, R. Mandal, Q. Zebeli, S.M. Dunn, D.S. Wishart

A metabolomics approach to uncover the effects of grain diets on rumen health in dairy cows

J. Dairy Sci., 95 (2012), pp. 6606-6623, 10.3168/jds.2012-5403

ArticleDownload PDFCrossRefView Record in ScopusGoogle Scholar 
B.N. Ametaj, Q. Zebeli, F. Saleem, N. Psychogios, M.J. Lewis, S.M. Dunn, J. Xia, D.S. Wishart

Metabolomics reveals unhealthy alterations in rumen metabolism with increased proportion of cereal grain in the diet of dairy cows

Metabolomics., 6 (2010), pp. 583-594, 10.1007/s11306-010-0227-6

CrossRefView Record in ScopusGoogle Scholar

S. Zhao, J. Zhao, D. Bu, P. Sun, J. Wang, Z. Dong

Metabolomics analysis reveals large effect of roughage types on rumen microbial metabolic profile in dairy cows

Lett. Appl. Microbiol., 59 (2014), pp. 79-85, 10.1111/lam.12247

CrossRefView Record in ScopusGoogle Scholar

I. Marcelino, A.M. de

Almeida, M. Ventosa, L. Pruneau, D.F. Meyer, D. Martinez, T. Lefrançois, N. Vachiéry, A.V. Coelho

Tick-borne diseases in cattle: applications of proteomics to develop new generation vaccines

J. Proteome, 75 (2012), pp. 4232-4250, 10.1016/j.jprot.2012.03.026

ArticleDownload PDFView Record in ScopusGoogle Scholar

L. Pruneau, A. Moumène, D.F. Meyer, I. Marcelino, T. Lefrançois, N. Vachiéry

Understanding Anaplasmataceae pathogenesis using “Omics" approaches

Front. Cell. Infect. Microbiol., 4 (2014), pp. 1-7, 10.3389/fcimb.2014.00086

Google Scholar

I. Marcelino, M. Ventosa, E. Pires, M. Möller, F. Lisacek, T. Lefrançois, N. Vachiery, A. V. Coelho

Comparative proteomic profiling of ehrlichia ruminantium pathogenic strain and its high-passaged attenuated strain reveals virulence and attenuation-Associated proteins

PLoS One, 10 (2015), pp. 1-23, 10.1371/journal.pone.0145328

CrossRefGoogle Scholar

A. Moumène, I. Marcelino, M. Ventosa, O. Gros, T. Lefrançois, N. Vachiéry, D.F. Meyer , A.V. Coelho

Proteomic profiling of the outer membrane fraction of the obligate intracellular bacterial pathogen Ehrlichia ruminantium PLoS One, 10 (2015), pp. 1-20, 10.1371/journal.pone.0116758

Google Scholar 
L. Pruneau, K. Lebrigand, B. Mari, T. Lefrançois, D.F. Meyer, N. Vachiery

Comparative transcriptome profiling of virulent and attenuated Ehrlichia ruminantium strains highlighted strong regulation of map1- and metabolism related genes

Front. Cell. Infect. Microbiol., 8 (2018), pp. 1-16, 10.3389/fcimb.2018.00153

Google Scholar

T. Nefefe, J. Liebenberg, M. van Kleef, H.C. Steyn, A. Pretorius

Innate immune transcriptomic evaluation of PBMC isolated from sheep after infection with E. ruminantium Welgevonden strain

Mol. Immunol., 91 (2017), pp. 238-248, 10.1016/j.molimm.2017.09.018

ArticleDownload PDFView Record in ScopusGoogle Scholar

M.A. Tjale, A. Pretorius, A. Josemans, M. Van Kleef, J. Liebenberg

Transcriptomic analysis of Ehrlichia ruminantium during the developmental stages in bovine and tick cell culture

Ticks Tick. Borne. Dis., 9 (2018), pp. 126-134, 10.1016/j.ttbdis.2017.09.014

ArticleDownload PDFView Record in ScopusGoogle Scholar

S. Antunes, J. Couto, J. Ferrolho, G.S. Sanches, J.O.M. Charrez, N. De La Cruz

Hernández, M. Mazuz, M. Villar, V. Shkap, J. De La Fuente, A. Domingos

Transcriptome and proteome response of Rhipicephalus annulatus tick vector to Babesia bigemina infection

Front. Physiol., 10 (2019), pp. 1-17, 10.3389/fphys.2019.00318

CrossRefView Record in ScopusGoogle Scholar

G.A.R. Bohaliga, W.C. Johnson, N.S. Taus, H.E. Hussein, R.G. Bastos, C.E. Suarez, G.A . Scoles, M.W. Ueti

Identification of proteins expressed by Babesia bigemina kinetes

Parasit. Vectors, 12 (2019), pp. 1-9, 10.1186/s13071-019-3531-7

Google Scholar

W.C. Johnson, N.S. Taus, K.E. Reif, G.A.R. Bohaliga, L.S. Kappmeyer, M.W. Ueti

Analysis of stage-specific protein expression during babesia bovis development within female rhipicephalus microplus

J. Proteome Res., 16 (2017), pp. 1327-1338, 10.1021/acs.jproteome.6b00947

CrossRefView Record in ScopusGoogle Scholar

[184]

A.M. Heekin, F.D. Guerrero, K.G. Bendele, L. Saldivar, G.A. Scoles, S.E. Dowd, C. Gon dro, V. Nene, A. Djikeng, K.A. Brayton 
Gut transcriptome of replete adult female cattle ticks, Rhipicephalus (Boophilus)

microplus, feeding upon a Babesia bovis-infected bovine host

Parasitol. Res., 112 (2013), pp. 3075-3090, 10.1007/s00436-013-3482-4

CrossRefView Record in ScopusGoogle Scholar

[185]

L. He, Y. Zhang, Q.L. Zhang, W.J. Zhang, H.H. Feng, M.K. Khan, M. Hu, Y.Q. Zhou, J.

L. Zhao

Mitochondrial genome of Babesia orientalis, apicomplexan parasite of water buffalo (Bubalus babalis, Linnaeus, 1758) endemic in China

Parasit. Vectors, 7 (2014), pp. 1-8, 10.1186/1756-3305-7-82

CrossRefView Record in ScopusGoogle Scholar

$$
\text { [186] }
$$

J. Yamagishi, M. Asada, H. Hakimi, T.Q. Tanaka, C. Sugimoto, S. Ichiro Kawazu

Whole-genome assembly of Babesia ovata and comparative genomics between closely related pathogens

BMC Genomics, 18 (2017), pp. 1-9, 10.1186/s12864-017-4230-4

CrossRefView Record in ScopusGoogle Scholar

$$
[187]
$$

L.M. González, K. Estrada, R. Grande, V. Jiménez-Jacinto, L. Vega-

Alvarado, E. Sevilla, J. De La

Barrera, I. Cuesta, Á. Zaballos, J.M. Bautista, C.A. Lobo, A. Sánchez-Flores, E. Montero

Comparative and functional genomics of the protozoan parasite Babesia divergens highlighting the invasion and egress processes

PLoS Negl. Trop. Dis., 13 (2019), pp. 1-23, 10.1371/journal.pntd.0007680

CrossRefView Record in ScopusGoogle Scholar

$$
\text { [188] }
$$

F. Martínez-Ocampo, R.E. Quiroz-Castañeda, I. Amaro-Estrada, E. Dantán-

González, J.F.P. De La Torre, S. Rodríguez-Camarillo

Whole-genome sequencing of mexican strains of anaplasma marginale: an approach to the causal agent of bovine anaplasmosis

Int. J. Genomics, 2020 (2020), 10.1155/2020/5902029

Google Scholar

$[189]$

K. Lis, I.G. Fernández de Mera, M. Popara, A. Cabezas-

Cruz, N. Ayllón, E. Zweygarth, L.M.F. Passos, M. Broniszewska, M. Villar, K.M. Kocan , M.F.B. Ribeiro, K. Pfister, J. de la Fuente

Molecular and immunological characterization of three strains of Anaplasma marginale grown in cultured tick cells

Ticks Tick. Borne. Dis., 6 (2015), pp. 522-529, 10.1016/j.ttbdis.2015.04.006

ArticleDownload PDFView Record in ScopusGoogle Scholar

$$
[190]
$$

S.A. Pierlé, G.K. Hammac, G.H. Palmer, K.A. Brayton 
Transcriptional pathways associated with the slow growth phenotype of transformed Anaplasma marginale

BMC Genomics, 14 (2013), 10.1186/1471-2164-14-272

Google Scholar

S. Diaz-Sanchez, A. Hernández-Jarguín, I.G. Fernández de

Mera, P. Alberdi, E. Zweygarth, C. Gortazar, J. de la Fuente

Draft genome sequences of Anaplasma phagocytophilum, A. marginale, and A. ovis Isolates from different hosts

Genome Announc., 6 (2018), pp. 8-10, 10.1128/genomeA.01503-17

Google Scholar

$$
\text { [192] }
$$

Z. Liu, A.M. Peasley, J. Yang, Y. Li, G. Guan, J. Luo, H. Yin, K.A. Brayton

The Anaplasma ovis genome reveals a high proportion of pseudogenes

BMC Genomics, 20 (2019), pp. 1-14, 10.1186/s12864-018-5374-6

CrossRefView Record in ScopusGoogle Scholar

[193]

A. Pereira, R. Parreira, A.J. Cotão, M. Nunes, M.L. Vieira, F. Azevedo, L. Campino, C. Maia

Tick-borne bacteria and protozoa detected in ticks collected from domestic animals and wildlife in central and southern Portugal

Ticks Tick. Borne. Dis., 9 (2018), pp. 225-234, 10.1016/j.ttbdis.2017.09.008

ArticleDownload PDFView Record in ScopusGoogle Scholar

V. Gillan, D.M. Simpson, J. Kinnaird, K. Maitland, B. Shiels, E. Devaney

Characterisation of infection associated microRNA and protein cargo in extracellular vesicles of Theileria annulata infected leukocytes

Cell. Microbiol., 21 (2019), pp. 1-13, 10.1111/cmi.12969

View Record in ScopusGoogle Scholar

M. Witschi, D. Xia, S. Sanderson, M. Baumgartner, J.M. Wastling, D.A.E. Dobbelaere

Proteomic analysis of the Theileria annulata schizont

Int. J. Parasitol., 43 (2013), pp. 173-180, 10.1016/j.ijpara.2012.10.017

ArticleDownload PDFView Record in ScopusGoogle Scholar

S. Ozubek, M. Aktas 
Molecular and parasitological survey of ovine piroplasmosis, including the first report of theileria annulata (Apicomplexa: Theileridae) in sheep and goats from Turkey

J. Med. Entomol., 54 (2017), pp. 212-220, 10.1093/jme/tjw134

CrossRefView Record in ScopusGoogle Scholar

T. Tonui, P. Corredor-

Moreno, E. Kanduma, J. Njuguna, M.N. Njahira, S.G. Nyanjom, J.C. Silva, A. Djikeng, R. Pelle

Transcriptomics reveal potential vaccine antigens and a drastic increase of upregulated genes during Theileria parva development from arthropod to bovine infective stages

PLoS One, 13 (2018), pp. 1-23, 10.1371/journal.pone.0204047

Google Scholar

K. Tretina, R. Pelle, J. Orvis, H.T. Gotia, O.O. Ifeonu, P. Kumari, N.C. Palmateer, S.B.A. Iqbal, L.M. Fry, V.M. Nene, C.A. Daubenberger, R.P. Bishop, J.C. Silva

Re-annotation of the Theileria parva genome refines $53 \%$ of the proteome and uncovers essential components of $\mathrm{N}$-glycosylation, a conserved pathway in many organisms

BMC Genomics, 21 (2020), pp. 1-12, 10.1186/s12864-020-6683-0

$\underline{\text { Google Scholar }}$

S. Preston, A. Jabbar, R.B. Gasser

A perspective on genomic-guided anthelmintic discovery and repurposing using Haemonchus contortus

Infect. Genet. Evol., 40 (2016), pp. 368-373, 10.1016/j.meegid.2015.06.029

ArticleDownload PDFView Record in ScopusGoogle Scholar 
D.G.L. Borges, J.T. Echeverria, T.L. De Oliveira, R.P. Heckler, M.G. De

Freitas, G.A. Damasceno-Junior, C.A. Carollo, F. De Almeida Borges

Discovery of potential ovicidal natural products using metabolomics

PLoS One, 14 (2019), 10.1371/journal.pone.0211237

Google Scholar

A.J. Dicker, N.F. Inglis, E.D.T. Manson, S. Subhadra, M. Illangopathy, R. Muthusamy, D .P. Knox

Proteomic analysis of mecistocirrus digitatus and haemonchus contortus intestinal protein extracts and subsequent efficacy testing in a vaccine trial PLoS Negl. Trop. Dis., 8 (2014), 10.1371/journal.pntd.0002909

Google Scholar

G. Sallé, R. Laing, J.A. Cotton, K. Maitland, A. Martinelli, N. Holroyd, A. Tracey, M. Be rriman, W.D. Smith, G.F.J. Newlands, E. Hanks, E. Devaney, C. Britton

Transcriptomic profiling of nematode parasites surviving vaccine exposure Int. J. Parasitol., 48 (2018), pp. 395-402, 10.1016/j.ijpara.2018.01.004 ArticleDownload PDFView Record in ScopusGoogle Scholar

R. Zhang, F. Liu, P. Hunt, C. Li, L. Zhang, A. Ingham, R.W. Li

Transcriptome analysis unraveled potential mechanisms of resistance to Haemonchus contortus infection in Merino sheep populations bred for parasite resistance

Vet. Res., 50 (2019), pp. 1-13, 10.1186/s13567-019-0622-6

CrossRefView Record in ScopusGoogle Scholar 
T. Wang, G. Ma, C.S. Ang, P.K. Korhonen, A.J. Stroehlein, N.D. Young, A. Hofmann, B .C.H. Chang, N.A. Williamson, R.B. Gasser

The developmental phosphoproteome of Haemonchus contortus

J. Proteome, 213 (2020), p. 103615, 10.1016/j.jprot.2019.103615

ArticleDownload PDFView Record in ScopusGoogle Scholar

J. Chen, F. Ma, X. Li, R. Zhao, X. Yang

Effect of norepinephrine treatment on Haemonchus contortus and its excretory products

Parasitol. Res., 118 (2019), pp. 1239-1248, 10.1007/s00436-019-06230-Z

View Record in ScopusGoogle Scholar

D.M. Ribeiro, S. Planchon, C.C. Leclercq, K. Raundrup, S.P. Alves, R.J.B. Bessa, J. Ren aut, A.M. Almeida

The muscular, hepatic and adipose tissues proteomes in muskox (Ovibos moschatus): differences between males and females

J. Proteome, 208 (2019), p. 103480, 10.1016/j.jprot.2019.103480

ArticleDownload PDFView Record in ScopusGoogle Scholar 